\title{
The Effect of Modifications of Activated Carbon Materials on the Capacitive Performance: Surface, Microstructure, and Wettability
}

\author{
Kouao Dujearic-Stephane ${ }^{1}$, Meenal Gupta ${ }^{1, *}$, Ashwani Kumar ${ }^{2}$, Vijay Sharma ${ }^{3}{ }^{(D}$, Soumya Pandit ${ }^{4}$, \\ Patrizia Bocchetta ${ }^{5, *}$ (D) and Yogesh Kumar ${ }^{6, *}$
}

1 Department of Physics, Material Research Laboratory, School of Basic Sciences and Research, Sharda University, Greater Noida 201310, India; ykb.ecs@gmail.com

2 Nanoscience Laboratory, Institute Instrumentation Centre, IIT Roorkee, Roorkee 247667, India; 01ashraj@gmail.com

3 Department of Physics, Shyam Lal College, University of Delhi, New Delhi 110032, India; nonuvijay@rediffmail.com

4 Department of Life Sciences, School of Basic Sciences and Research, Sharda University, Greater Noida 201310, India; soumya.pandit@sharda.ac.in

5 Dipartimento di Ingegneria dell'Innovazione, Università del Salento, via Monteroni, 73100 Lecce, Italy

6 Department of Physics, Atma RamSanatan Degree College, University of Delhi, New Delhi 110 021, India

* Correspondence: meenal.gupta@sharda.ac.in (M.G.); patrizia.bocchetta@unisalento.it (P.B.); ykumar@arsd.du.ac.in (Y.K.)

\section{check for} updates

Citation: Dujearic-Stephane, K.; Gupta, M.; Kumar, A.; Sharma, V.; Pandit, S.; Bocchetta, P.; Kumar, Y. The Effect of Modifications of Activated Carbon Materials on the Capacitive Performance: Surface, Microstructure, and Wettability. J. Compos. Sci. 2021, 5, 66. https:// doi.org/10.3390/jcs5030066

Academic Editor:

Francesco Tornabene

Received: 2 February 2021

Accepted: 20 February 2021

Published: 26 February 2021

Publisher's Note: MDPI stays neutral with regard to jurisdictional claims in published maps and institutional affiliations.

Copyright: (c) 2021 by the authors. Licensee MDPI, Basel, Switzerland. This article is an open access article distributed under the terms and conditions of the Creative Commons Attribution (CC BY) license (https:/ / creativecommons.org/licenses/by/ $4.0 /)$.
Abstract: In this review, the efforts done by different research groups to enhance the performance of the electric double-layer capacitors (EDLCs), regarding the effect of the modification of activated carbon structures on the electrochemical properties, are summarized. Activated carbon materials with various porous textures, surface chemistry, and microstructure have been synthesized using several different techniques by different researchers. Micro-, meso-, and macroporous textures can be obtained through the activation/carbonization process using various activating agents. The surface chemistry of activated carbon materials can be modified via: (i) the carbonization of heteroatomenriched compounds, (ii) post-treatment of carbon materials with reactive heteroatom sources, and (iii) activated carbon combined both with metal oxide materials dan conducting polymers to obtain composites. Intending to improve the EDLCs performance, the introduction of heteroatoms into an activated carbon matrix and composited activated carbon with either metal oxide materials or conducting polymers introduced a pseudo-capacitance effect, which is an additional contribution to the dominant double-layer capacitance. Such tricks offer high capacitance due to the presence of both electrical double layer charge storage mechanism and faradic charge transfer. The surface modification by attaching suitable heteroatoms such as phosphorus species increases the cell operating voltage, thereby improving the cell performance. To establish a detailed understanding of how one can modify the activated carbon structure regarding its porous textures, the surface chemistry, the wettability, and microstructure enable to enhance the performance of the EDLCs is discussed here in detail. This review discusses the basic key parameters which are considered to evaluate the performance of EDLCs such as cell capacitance, operating voltage, equivalent series resistance, power density, and energy density, and how these are affected by the modification of the activated carbon framework.

Keywords: activated carbon; carbon precursor; BET analysis; nano-structured porous electrode; supercapacitors

\section{Introduction}

Although intense research has been conducted to develop high-performance energy storage devices based on conventional energy resources fossil fuels, the energy demand 
still increases. The impact of these energy resources on our environment becomes more preoccupant [1]. Therefore, there is a need to meet the demand of energy by developing clean and renewable forms of energy. To reduce fossil fuel consumption, it is necessary to develop high-performance electrical energy conversion devices based on renewable energy sources, which has become a great challenge for the researchers [2]. In this respect, the development of electrical energy production devices based on renewable energy sources, such as solar or wind energy, is promising. However, owing to the high fluctuation of the generated energy, efforts still need to be made.

In light of the earlier discussed challenges, energy storage devices with greater storage capacity with more retention value are required. Energy storage devices such as supercapacitors and batteries are used every day in our lives to store electrical energy for our electronic devices [3]. Batteries have greatly attracted the researchers' attention owing to their high energy density. Batteries have been mostly used as a dominant energy storage device for electric vehicles and portable electronics [4]. However, the relatively lower power density currently limited their application in electronics devices that required high power density such as tramways and energy harvesting systems. In addition, the volatility of the electrolyte solution decreases the device lifetimes, and the exothermic reactions generate combustible gases, melt the separator, and create short circuits. Therefore, their safety issues and low power density limit their application to various electronic products [4]. Supercapacitors provide high power density at a short time, and their long lifetimes are more suitable for electronic device applications requiring energy input in a short time interval [5]. Supercapacitors are used complementary to batteries in order to extend batteries' lifetime. A supercapacitor is also considered as a future clean alternative energy storage device to batteries and fossils fuels due to their safety performance.

The power output of supercapacitors depends on the properties of the materials used in each component, including current collectors, electrodes, electrolyte, and the separator but also the way these components are designed, matched, and combined to form the cell [6]. According to the charge storage mechanism, a supercapacitor is distinguished as either of two types: EDLCs and pseudocapacitors. This review focus on the efforts made of improving the performance of EDLCs electrodes. EDLCs electrodes are synthesized from a different type of active materials. Carbonaceous materials are also used as electrode materials at large scale. These electrodes are of low cost due to the universally available and renewable carbon precursor sources [7]. Various electrodes based on carbon materials with different structures and porous textures have been reported in the literature. Several biomasses have also been investigated as a carbon precursor due to their renewable character to achieve high performance and sustainable supercapacitor devices [8]. However, supercapacitor application is currently limited by several challenges, such as fast self-discharge and low energy density. To increase the energy density and make cheaper supercapacitors available in the market, carbon materials with suitable microstructures and porous textures are seen as a promising material for the synthesis of supercapacitor electrodes by researchers, due to the easy availability of renewable precursors [9].

Among the various forms of carbon materials used in the synthesis of supercapacitor electrodes, porous carbon is one of the best candidates, due to both the texture of its surface (porosity, pore distribution, specific surface area) and its surface chemistry which can be easily modified to improve its performance [10]. Significant efforts have been made to design the appropriate microstructure and porous texture of carbon-based materials with satisfactory electrochemical performance. In general, the microstructure of a material is related to the arrangement of its internal component and strongly governs the electronic and thermal conductivity of the material. A suitable porous texture is essential to optimize the charge accumulation during the charge process. Hence, the microstructure and porous texture are important parameters that must be taken into account when designing the active material. The performance of these electrodes may be further improved by surface modi- 
fication via (i) post-treatment of carbon materials with reactive heteroatom sources, and (iii) composited activated carbon with either metal oxide materials or conducting polymers.

This review describes the performance enhancement of SCs electrodes based on activated carbon material, through the modification of both its surface chemistry and microstructure, with the objective of understanding the effect of modifications of activated carbon materials on the cell capacitance performance, the electrical conductivity, and the wettability of the electrodes. First, the electrical properties of the electrodes based on porous carbon materials and the evaluation of its performances are introduced. The effect of the porous texture on the electrode's performance is discussed in detail, and the performance evaluation is outlined. Then, the benefic effect of heteroatoms-doping in the electrochemical behavior of the EDLCs electrodes is discussed. Finally, the performance of supercapacitor electrodes based on activated composite carbon materials combined with metal oxides or conducting polymers is explained and discussed.

\section{Designing and Parameters of the Electrical Double Layer Capacitors (EDLCs)}

The parameters measured to study the performance of the EDLC are as follows: cell capacity, operating voltage, equivalent series resistance, power density, and energy density. In practice, only the measurement of three parameters such as cell capacity $\left(C_{\mathrm{T}}\right)$, operating voltage $\left(V_{0}\right)$, and equivalent series resistances ESR is necessary because the specific power density and the specific energy density depend on the three essential parameters above by the following relationships:

$$
\begin{aligned}
& \text { Power Density }=\frac{V_{\mathrm{O}}^{2}}{4 \mathrm{mR}_{\mathrm{ES}}} \\
& \text { Energy Density }=\frac{C_{\mathrm{T}} V_{\mathrm{O}}^{2}}{2 \mathrm{~m}}
\end{aligned}
$$

Two approaches are usually used for the EDLCs performance measurement: threeelectrode and two electrode systems. The three-electrodes configuration consists of one working electrode, a reference electrode ( $\mathrm{Ag} / \mathrm{AgCl}$ or saturated electrode) maintained at fixed potential defines a base potential in the three electrodes system, and a counter electrode (platinum wire) used to balance the reactions accruing in the working electrode. Figure 1 shows a three-electrode arrangement. The three-electrode configuration is useful in the investigation of the chemistry of the active electrode surface as well as the redox behavior of the active electrode material [11]. It has been reported that the three-electrode system is not very accurate in the measurement of the cell capacitance errors have been observed when the three-electrode system is used to measure the capacitance [11]. Two electrode systems consist of two working electrodes: a cathode negatively charged, and an anode positively charged with electrolyte sandwiched between these two electrodes. The anodic and cathodic compartment cab be also separated by a membrane that permits the selective passage of some ions and avoid short circuits. The choice of the separator must be based on following considerations: non-conducting materials to prevent electron transport between electrodes, electrolyte ions permeable with minimum ionic resistance, chemical resistance to electrolytes and electrodes materials, and mechanical resistance to pressure and volume changes such as swelling, easy wetted by electrolytes [12].

\subsection{Cell Capacitance CT}

The cell capacitance measure total electrical charge stored under a given voltage applied, $C_{\mathrm{T}}=\frac{\Delta \mathrm{Q}}{\Delta \mathrm{V}}$ [Farad], $\Delta \mathrm{Q}$ is the total charge stored and $\Delta \mathrm{V}$ the potential range defined.

The cell capacitance can be evaluated via cyclic voltammetry $(\mathrm{CV})$ measurement. This technique consists of applying a voltage to the working electrode, relative to the reference electrode maintained at a fixed potential. The working electrode is swept linearly back 
and forth in a given potential range. The capacitance is then calculated by analyzing the recorded $\mathrm{CV}$ graph according to:

$$
C_{\mathrm{T}}=\frac{\int \mathrm{idV}}{2 \Delta \mathrm{V} \mathrm{V}_{\mathrm{s}}}
$$

where $i$ is the current density, $\Delta \mathrm{V}$ is the potential interval, and Vs is the potential scan rate. The capacitance can also be evaluated by analyzing the galvanostatic charge-discharge (GCD) curves. Here, the working electrode is subjected to a constant current density (i) $(\mathrm{A} / \mathrm{g})$, and the potential response is measured $(\mathrm{dV})$ with respect to time $(\mathrm{dt})$, and the capacitance is calculated using the following equation:

$$
C_{\mathrm{T}}=\frac{\mathrm{i}}{\mathrm{dV} / \mathrm{dt}}
$$

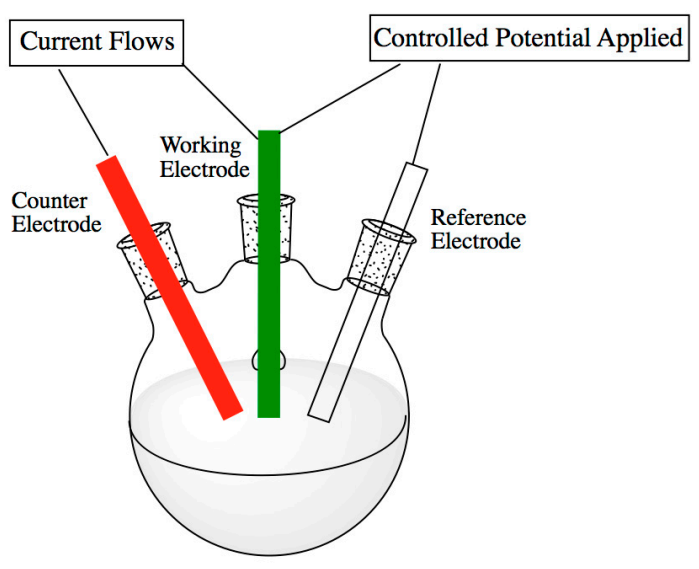

Figure 1. A typical schematic presentation of a three-electrode arrangement. Reproduced from [11] under license CC BY-NC-SA 3.0.

The capacitance can also be evaluated by Electrochemical Impedance Spectroscopy (EIS) in addition to CV and GCD. This technique records the impedance of a material as a function of frequency by imposing a sinusoidal AC voltage of low amplitude of about 2-10 $\mathrm{mV}$ over the applied steady state potential. The capacitance is then calculated using the formula:

$$
C_{\mathrm{T}}=\frac{-1}{2 \pi \mathrm{f} \operatorname{Im}(\mathrm{Z})}
$$

where $\mathrm{f}$ is the frequency, and $\operatorname{Im}(\mathrm{z})$ the imaginary part of the impedance.

\subsection{Equivalent Series Resistance (ESR)}

The sum of all the resistances of the EDLC is termed as equivalent series resistance which is an essential parameter that regulates the power output of the device. It contains several ohmic drops located into the electrolyte, the electrodes, and at the electrode/current collector interfaces [13].

The equivalent series resistance can be evaluated using either GCD or EIS. The evaluation of (RES) through GCD is related to the analysis of IR drop or voltage drop from charge discharging curve and using Ohm law formula:

$$
\mathrm{RES}=\frac{V_{\text {drop }}}{\Delta \mathrm{I}}
$$

where $V_{d r o p}$ and $\Delta \mathrm{I}$ are the voltage and current of I-R drop, respectively.

From the EIS test, shown in Figure 2a, ESR is evaluated by linearly interpolating the high-frequency arc of the Nyquist plot to $\operatorname{Im}(Z)=0$. As evidenced in the GDC curve 
Figure $2 b$, the voltage drop can be visually estimated from during the discharge curve during galvanostatic cycling [13].

\subsection{Operating Voltage (VO)}

The operating voltage Vo is defined as the suitable potential window within which a cell operates safely. It can be evaluated by using either CV or GCD test. Figure $2 b$ illustrates the determination of $\mathrm{VO}$ and ESR using the GCD test. The I-R drop represents the drop voltage $\Delta \mathrm{V}$ during the discharge stage. By measuring the IRdrop the equivalent series resistance is determined by Equation (6).
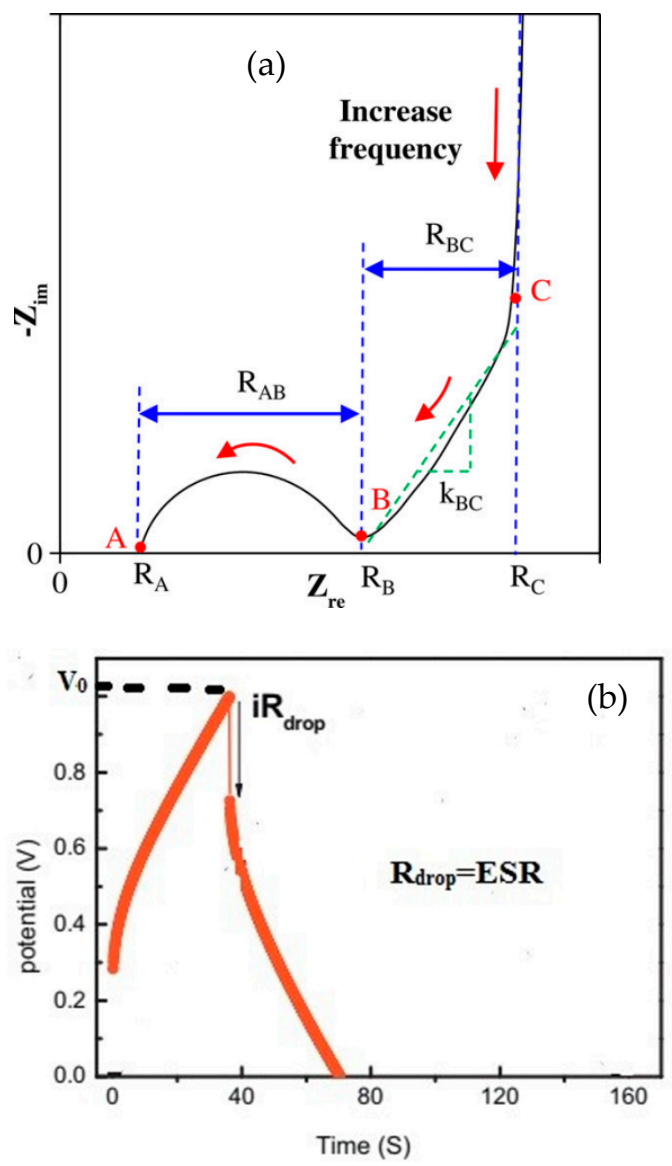

Figure 2. Equivalent Series Resistance (ESR) $\left(R_{\mathrm{A}}\right)$ evaluation using (a) the Nyquist plot. Reprinted with permission from [13]. Copyright (2018) American Chemical Society. (b) the GDC test. Reprinted from [14] with permission from Elsevier.

\section{Types and Properties of Porous Carbon Materials}

Various carbon allotropes are used in the literature to synthesize electrodes for supercapacitor due to its good conductivity $10^{3} \mathrm{~S} / \mathrm{m}$ for graphene [15] and good electrochemical stability. Carbon electrodes show great thermal resistance in contact with both aqueous and organic solutions and under a large potential window. Activated carbons materials are known for their high specific surface area by developing physical or chemical methods. Figure 3 shows the different forms of carbon used in supercapacitors as an electrode material. Various forms of carbon have been used in the literature for the synthesis of electrodes of supercapacitors. Porous carbons prepared using the template method are more attractive because of their large specific surface and their porous textures. 


\subsection{Properties of Porous Carbon}

The adsorption performance of the synthesized porous carbon is defined by various parameters. Specific surface area, porosity, and ash content are fundamental features that establish the activated carbon electrochemical activity.

\subsubsection{Specific Surface Area}

Specific surface area is the part of the total surface area where the phenomenon of adsorption occurs. Large specific surface area may be obtained due to the presence of many pores developing during the activation and carbonization process. The optimal temperature to get the maximum specific surface area depends on the thermal stability of the precursor. Harry Marsh and Francisco Rodriguez-Reinoso [16] have studied the variation of the specific surface area with respect to the carbonization temperature for two different precursors, polyvinylidene chloride [PVDC] and polyfurfuryl alcohol [PFA]. They found that the maximum value of the specific surface $\left(1200 \mathrm{~m}^{2} / \mathrm{g}\right)$ is obtained at $1300{ }^{\circ} \mathrm{C}$ for the PVDC, while that of the PFA is approximately $450 \mathrm{~m}^{2} / \mathrm{g}$ and is obtained at approximately $750^{\circ} \mathrm{C}$. The particle size distribution is also one of the important parameters that must be considered in order to maximize the specific surface of the carbon material. As the particle size reaches to nano-size, the specific surface area increases and, in that case, more particles are distributed on the active areas of the material thereby enhancing reactivity, catalytic activity and general performance of the carbon electrode.
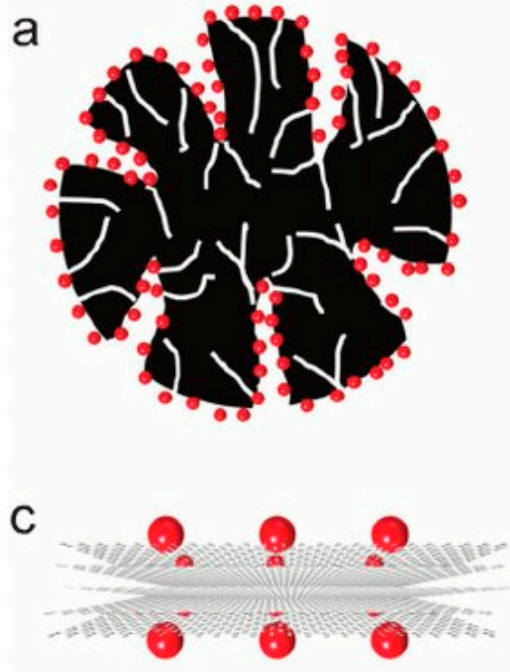

b

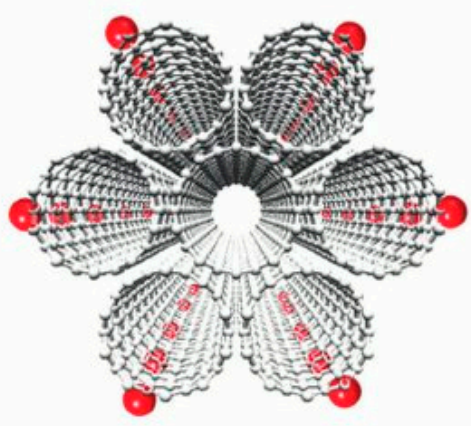

d

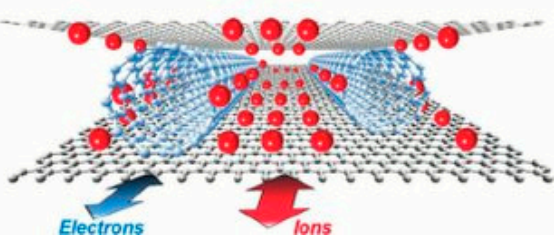

Figure 3. Different form of carbon used in supercapacitors. (a) Activated porous carbon. (b) Singlewalled carbon nanotube (SWCNT) bundles. (c) Pristine graphene. (d) Graphene/CNT composite. Used with permission of ROYAL SOCIETY OF CHEMISTRY, from [15]; copyright (1999), permission conveyed through Copyright Clearance Center, Inc.

\subsubsection{Porosity}

The efficiency of the activated carbon to absorb the solute molecules is controlled by the material's internal surface accessibility. The pore texture (pore shape, pore size, pore volume) and their distribution are the most important parameters which define the adsorption capacity of the materials. The International Union of Pure and Applied Chemistry (IUPAC) recommendation define pores as: micropores (width $<2 \mathrm{~nm}$ ), mesopores $(2 \mathrm{~nm}<$ width $<50 \mathrm{~nm}$ ), and macropores (width $>50 \mathrm{~nm}$ ). The macropores and mesopores enhance the charge propagation efficiency through the microspores. The specific surface area generated by the presence of macropores is very small, and the rate of adsorption is negligible in macropores [17]. The size of the solute molecules is usually correlated to the 
micropores size, and it enhances the adsorption of ions within micropores. In EDLCs the electrostatic attraction takes place mainly in the micropores.

\subsubsection{Ash Content}

The amount of ash containing in the activated carbon is derived from the raw material used as a precursor, but also occur during to the activated carbon preparation process. The ash presents in the activated carbon strongly affect the wettability of the material. As the amount of ash increase in the material, it becomes more hydrophilic [18].

\subsection{Activated Carbon (AC)}

Activated carbon is a carbon-based material, characterized by a high degree of structural disordered with respect to the graphitic structure. Activated carbons are synthesized in order to obtain high porous texture and large surface area. Activated carbon has received great attraction owing to their various applications in water and air purification as well as electrodes for supercapacitor and fuel cells. The functionality of the porous structure depends on the pore size: meso- and macro- pores allow the diffusion of charged species whereas micro-pores favor the accumulation of charged species increasing the specific capacitance [8].

The synthesis of a well-defined porous texture of the porous carbon is necessary for its high performance in different devices because the mass transfer through the pores greatly influences the efficiency of the device, and hence the development of synthesis technique that enables activated carbon with well-defined micro-, meso-, and macroporous texture is crucial for researchers. Various techniques have been proposed in the literature for the synthesis of activated carbon and can be summarized into two categories, traditional methods or (carbonization/activation) approach and template synthesis. The traditional methods include chemical activation, physical activation, and the combination of chemical and physical activation processes. The traditional methods listed above cannot provide porous carbon with precise control on pore size and distribution of pores, therefore are unable to obtain uniform pores in porous texture. The porous texture of the carbon material is generated during the activation steps, and hence increases the active carbon surface, thereby improving the adsorption efficiency of the material. The chemical and physical activation process requires a carbon precursor containing high $\mathrm{C}$ percentages, such as coal, lignite, wood, lignin, petroleum coke, and polymers, as PVC, PVA, etc. The choice of the carbonaceous precursor should take into account the following factors: high carbon content, low inorganic content (low ash), potential extent of activation, high density and sufficient volatile content and inexpensive materials (easily available). This method involves two steps carbonization and activation. The carbonization process involves drying and removing non-carbonaceous species from the precursor by thermal decomposition of the carbonaceous material $\left(400-600^{\circ} \mathrm{C}\right)$ producing a fixed mass of carbon. The role of activation is to expand the pores size generated during carbonization therefore to facilitate the entrance of ions and provide them a high surface area. Table 1 shows the composition of carbonized material from various raw carbon precursors used in the literature.

Table 1. Composition of carbonized materials from various carbon precursors and related references.

\begin{tabular}{|c|c|c|c|c|c|c|c|}
\hline Raw Material & $\begin{array}{c}\text { Volatiles } \\
\text { (wt } \%)\end{array}$ & $\begin{array}{c}\text { Carbon } \\
(w t \%)\end{array}$ & $\begin{array}{c}\text { Ash } \\
(w t \%)\end{array}$ & $\begin{array}{c}\text { Surface Area, } \\
\text { SSA } \\
\left(\mathrm{m}^{2} / \mathrm{g}\right)\end{array}$ & $\begin{array}{c}\text { Specific } \\
\text { Capacitance } \\
(\mathrm{F} / \mathrm{g})\end{array}$ & $\begin{array}{c}\text { Current } \\
\text { Density/Scan } \\
\text { Rate }\end{array}$ & Refs. \\
\hline Coconut shell & 77.19 & 22.10 & 0.71 & 1532 & 228 & $5 \mathrm{mV} / \mathrm{s}$ & {$[19,20]$} \\
\hline Wheat straw & 82.12 & 10.98 & 6.90 & 892 & 222 & $8 \mathrm{~A} / \mathrm{g}$ & {$[19,21]$} \\
\hline Rice husk & 61.81 & 16.95 & 21.24 & 1442 & 233 & $2 \mathrm{~A} / \mathrm{g}$ & {$[19,22]$} \\
\hline Sugarcane bagasse & 83.66 & 13.15 & 3.20 & 1788 & 300 & $0.25 \mathrm{~A} / \mathrm{g}$ & {$[19,23]$} \\
\hline Bamboo wood & 86.80 & 11.24 & 1.95 & 2960 & 144 & $5 \mathrm{~A} / \mathrm{g}$ & {$[19,24]$} \\
\hline Olive stones & 78.30 & 19.50 & 2.20 & 1626 & 175 & $10 \mathrm{~A} / \mathrm{g}$ & {$[25,26]$} \\
\hline Almond shell & 80.50 & 18.40 & 1.10 & 2144 & 334.2 & $10 \mathrm{mV} / \mathrm{s}$ & {$[25,27]$} \\
\hline Sunflower seed shell & 84.70 & 11.70 & 3.60 & 2509 & 311 & $0.25 \mathrm{~A} / \mathrm{g}$ & {$[28,29]$} \\
\hline Cotton stalk & 76.10 & 18.80 & 5.10 & 1964.46 & 221 & $10 \mathrm{~A} / \mathrm{g}$ & {$[30,31]$} \\
\hline Peanut shell & 84.90 & 13.40 & 1.70 & 3103 & 298 & $10 \mathrm{~A} / \mathrm{g}$ & {$[32,33]$} \\
\hline Rice straw & 65.47 & 15.86 & 18.67 & 1007 & 190 & $10 \mathrm{~A} / \mathrm{g}$ & {$[34,35]$} \\
\hline Switch grass & 76.69 & 14.34 & 8.97 & 1272 & 140 & $0.1 \mathrm{~A} / \mathrm{g}$ & {$[34,36]$} \\
\hline Willow wood & 82.22 & 16.07 & 1.71 & 2800 & 394 & $1 \mathrm{~A} / \mathrm{g}$ & {$[34,37]$} \\
\hline Corn straw & 73.15 & 19.19 & 7.65 & 2257 & 227 & $5 \mathrm{mV} / \mathrm{g}$ & {$[38,39]$} \\
\hline Rape straw & 76.54 & 17.81 & 4.65 & 748.6 & 361 & $1 \mathrm{~A} / \mathrm{g}$ & {$[33,40]$} \\
\hline Miscanthus & 79 & 11.4 & 9.6 & 3024 & 110 & $50 \mathrm{mV} / \mathrm{s}$ & {$[41,42]$} \\
\hline
\end{tabular}


Table 1. Cont.

\begin{tabular}{|c|c|c|c|c|c|c|c|}
\hline Raw Material & $\begin{array}{c}\text { Volatiles } \\
\text { (wt } \%)\end{array}$ & $\begin{array}{c}\text { Carbon } \\
(w t \%)\end{array}$ & $\begin{array}{c}\text { Ash } \\
(w t \%)\end{array}$ & $\begin{array}{c}\text { Surface Area, } \\
\text { SSA } \\
\left(\mathrm{m}^{2} / \mathrm{g}\right)\end{array}$ & $\begin{array}{c}\text { Specific } \\
\text { Capacitance } \\
\text { (F/g) }\end{array}$ & $\begin{array}{c}\text { Current } \\
\text { Density/Scan } \\
\text { Rate }\end{array}$ & Refs. \\
\hline pineapple leaves & - & 42.94 & 3.57 & 1681 & 202 & $5 \mathrm{mV} / \mathrm{s}$ & {$[46,47]$} \\
\hline Banana leaves & 41.3 & 46.5 & 12.2 & 1230 & 400 & $0.5 \mathrm{~A} / \mathrm{g}$ & {$[48,49]$} \\
\hline Moringa oleifer & 36.45 & 42.76 & 12.71 & 2345 & 203 & $0.5 \mathrm{~A} / \mathrm{g}$ & {$[50,51]$} \\
\hline Orange peels & 76.52 & 20.39 & 3.09 & 2160 & 460 & $1 \mathrm{~A} / \mathrm{g}$ & {$[52,53]$} \\
\hline potato peels & 60.85 & 27.85 & 6.96 & 960 & 269 & $1 \mathrm{~A} / \mathrm{g}$ & {$[54,55]$} \\
\hline argan shell & 61 & 28 & 1.5 & 2100 & 355 & $125 \mathrm{~mA} / \mathrm{g}$ & {$[56,57]$} \\
\hline Almondshells & 76.00 & 20.71 & 3.29 & - & - & - & {$[19,20]$} \\
\hline Olive pitts & 82.00 & 16.28 & 1.72 & - & - & - & {$[19,21]$} \\
\hline Wet grains & 83.18 & 13.58 & 2.58 & - & - & - & {$[19,22]$} \\
\hline Marabú & 81.30 & 17.20 & 1.50 & - & - & - & {$[19,23]$} \\
\hline Soplillo & 77.80 & 20.70 & 1.50 & - & - & - & {$[19,24]$} \\
\hline
\end{tabular}

Physical activation can be achieved using oxidizing gases, for example, steam or $\mathrm{CO}_{2}$ above $800{ }^{\circ} \mathrm{C}$. Chemical activation requires the impregnation of precursors with activating species as $\mathrm{H}_{3} \mathrm{PO}_{4}, \mathrm{KOH}$, and $\mathrm{ZnCl}_{2}$.

\subsection{Porous Carbon Synthesized Using Template Route}

The template synthesis is used to create a uniform pore size. A better control of pore size can be achieved via the use of a proper template. Syntheses of microporous carbon, mesoporous carbon, and macroporous carbon have been done by researchers using Zenolite, mesoporous silica, and synthetic silica opal as templates, respectively [58]. The general template synthesis route goes on through three typical passages: (1) Synthesis of the composite of carbon precursor and inorganic template, (2) Carbonization of the prepared composite material, and (3) Removal of the inorganic template. Figure 4 gives an illustration of various templates used in literature for the synthesis of micro-, meso-, and macroporous carbon for supercapacitor applications. Liu Wan et al. [59] synthesized highly mesoporous texture using a soft-templating agent (surfactant-F127). In such methods, during the carbonization process surfactant, F127 decomposes, resulting in the formation of mesopores. Their work confirmed that the obtained remarkable mesoporous texture of electrodes facilitates the diffusion of the ions, thereby reducing the charge-transfer resistance of the electrodes [59]. It is also important to underline that the charge storage mechanism through the porous texture still very complex [60]. In general, the well-balanced micro/meso porosity is an important criterion, which must be taken into account in the synthesis of the porous texture of the electrode materials. Li Sun et al. [60] prepared porous carbon using a template as porogent tetraethyl orthosilicate (TEOS). The porous texture consists of a coexistence of micropores and mesopores carbon with large specific surface area $1027 \mathrm{~m}^{2} / \mathrm{g}$. The good capacitance behavior observed $(293 \mathrm{~F} / \mathrm{g}$ at $1 \mathrm{~A} / \mathrm{g})$ shows the benefic effect of the electrodes' porous texture, which enables short ion diffusion distance due to the presence of mesopores through the micropores, thereby facilitating the accessibility of the electrodes to electrolyte's ions. Supercapacitor devices are electrical storage devices that are an intermediate between conventional capacitors (CSC) and batteries. Infact, they can provide stored electrical energy that is superior to CSC and electrical power density superior to batteries.

However, poor wettability of the carbon-based electrodes induces high resistance to the diffusion of the ions within the micropores during charge/discharge process, and it limits the specific capacitance value [61].

\subsection{Effect of Activated Carbon Microstructure and Porous Texture on EDLC's Performance}

The application of supercapacitors is currently limited by several challenges. One of the main drawbacks is the trade-off between energy density and power density by parameter time. To obtain the best compromise between energy density and power density, one the best approach is to design and control the microstructure and porosity of electrodes 
based on activated carbon [23]. Figure 5 gives an illustration of the improvement of the cell performance by designed an appropriate carbon porous texture. Figure 5a shows an increase of the charge accumulation at the electrolyte/electrode interface due to the porous electrode texture. The increase of charge accumulation at the electrode interface can enhance the specific capacitance, thereby improving the energy density of the prepared cell. Figure $5 \mathrm{~b}$ describes how fast the electrolyte can seep through a well-designed porous texture, thus facilitating mass transport at the electrode/electrolyte interface.

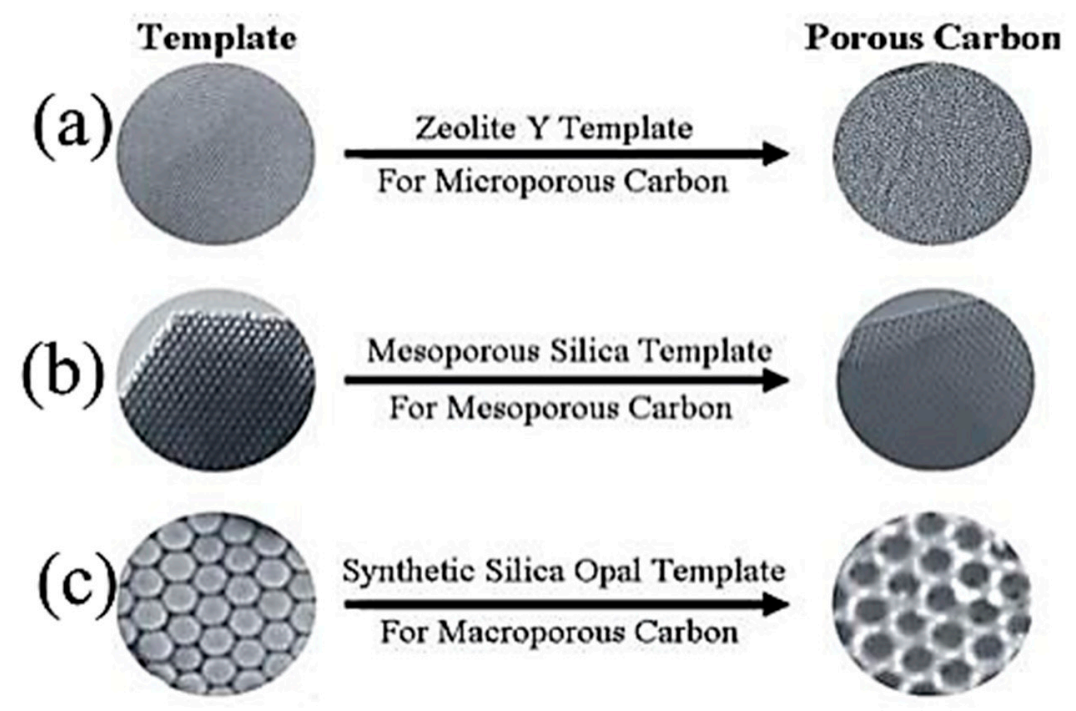

Figure 4. (a) Microporous, (b) mesoporous, and (c) macroporous carbon materials were synthesized using zeolite, mesoporous silica, a synthetic silica opal, respectively [58].

\subsubsection{Impact of the Surface Texture on the Capacitance}

The textural characteristics of the activated carbon are defined by the pores size, pores volume, pores distribution, and the specific surface area. The capacitance is linearity proportional to the electrodes active surface area, and therefore the EDLC's performance strongly depends on the electrodes texture. Activated carbon through its porous texture significantly increases the electrode active surface area, thereby enhances the capacitance. However, activated carbons even with specific surface area ranging up to $2500-3000 \mathrm{~m}^{2} / \mathrm{g}$ show very small specific capacitance. It may be because not all pores are effective in charge accumulation. Therefore, understanding the correlation between the pore size and the electrolyte ions size is one of the key challenges to improve EDLC's storage capability. Recently, extensive research has been done to design best pore size to achieve highest specific capacitance. Production of activated carbon comes from the carbonization of various raw precursors (coal, wood, requires high carbon content carbon precursor such as coal, lignite, wood, peat, nutshell, coconut shell, lignin, petroleum coke, etc.) as well as synthesis precursors (PVC, PVA, PVDC, PFA, etc.) followed by the physical or chemical activation process. The total surface area of the obtained activated carbon is conventionally divided into two parts: internal surface area constituted to micropores and external surface including mesopores and macropores. The work of Alaya et al. [64] showed that the surface area located inside the mesopores defines the greatest proportion of the total active area. Therefore, the surface area located inside the mesopores and macropores would be only a small proportion of the total active area of the activated carbon. In other words, the surface area located inside the macrospores is negligible compared to that of the mesopores and microspores. The electrostatic attraction associated with the double layer formation takes place mainly in micropores; however, the presence of mesopores and macropores are necessary for efficient charge propagation. Raymundo-Piñero et al. [65] investigated the relationship between the nanoporous texture of activated carbons and their capacitance properties using both aqueous and organic electrolyte and bituminous 
coal as carbon precursor. Their results showed that the efficiency of double-layer formation in EDLC is optimal for the pore size around $0.7 \mathrm{~nm}$ for aqueous media and $0.8 \mathrm{~nm}$ in organic electrolytes as reported in [65]. Table 2 shows the strong dependence of both the specific capacitance and the equivalent series resistance with the microspores volume, established in the work of Qiao et al. [66]. Wang et al. [67] observed the similar results, by synthesizing two electrode materials based on activated carbon, with two different porous texture using petroleum pitch as carbon precursor, one electrode with high microporous texture and other with high mesoporous texture. The results showed that the electrode with large microporous textures exhibits higher specific surface area as well as higher specific capacitance compared to the electrode with large mesoporous textures. The above results confirm that designing and controlling the porous textures of the electrodes based on activated carbon material is necessary to enhance the specific capacitance.

(a)

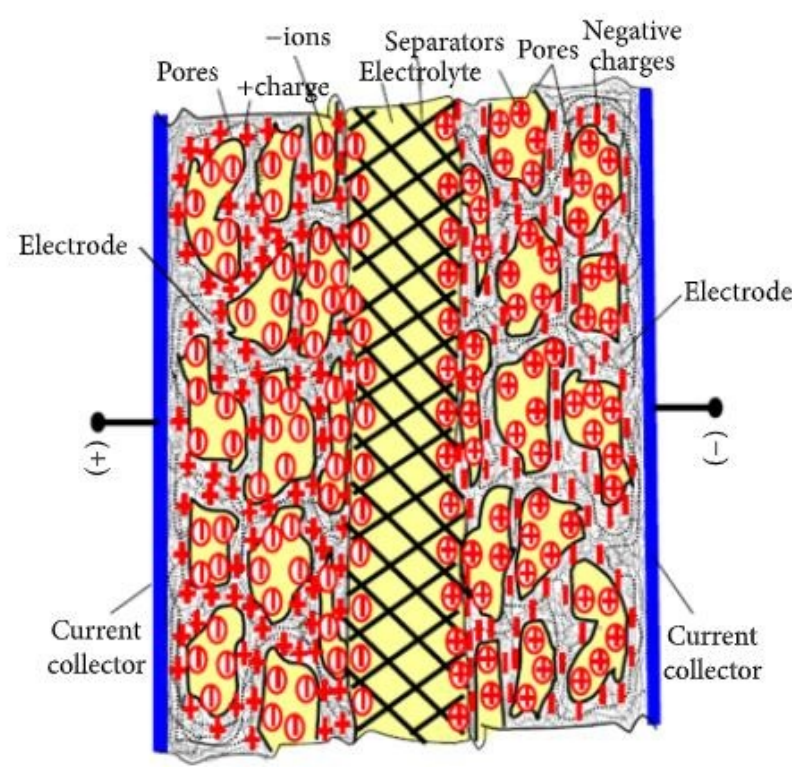

(b)

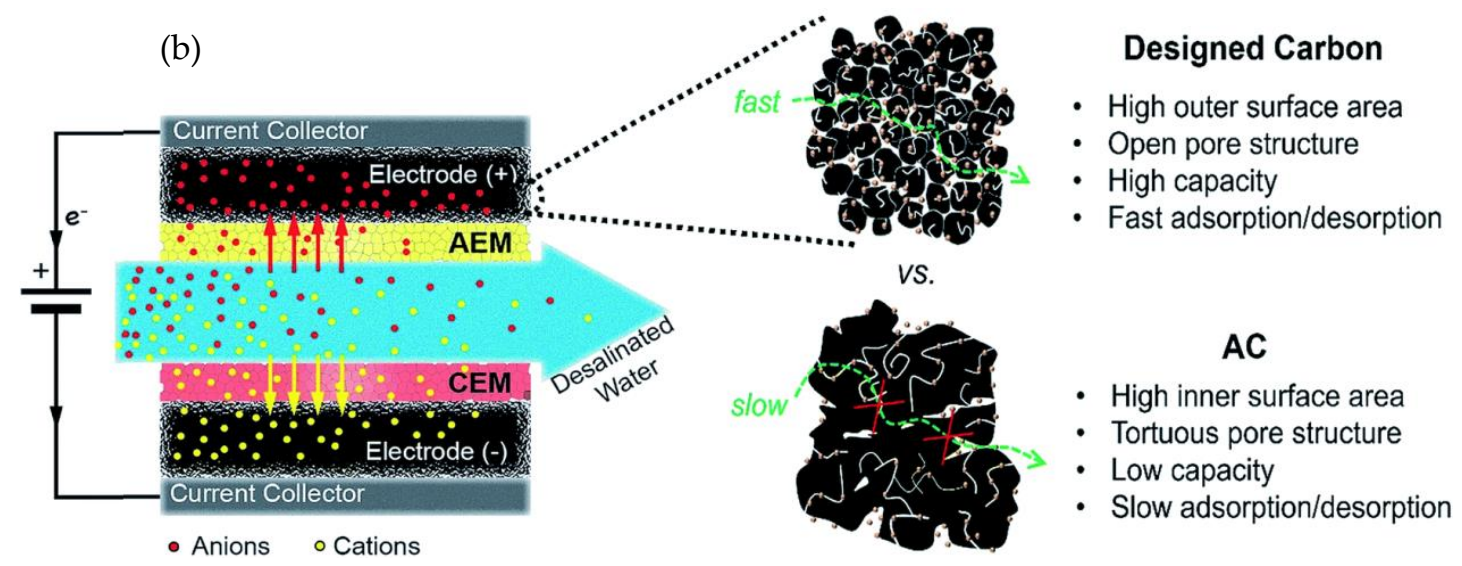

Figure 5. (a) Schematic illustration of a charged supercapacitor based on porous electrodes. Reprinted from [62] copyright (2008), with permission from Elsevier. (b) Design criteria of high-performance porous carbon materials. Used with permission of Royal Society of Chemistry (Great Britain), from [63] copyright 2013; permission conveyed through Copyright Clearance Center, Inc.

3.4.2. Impact of the Activated Carbon Microstructure on the Equivalent Series Resistance

The microstructure describes the average positions of atoms within the unit cell of the materials, and strongly affects the electrical conductivity of the materials. The EDLC's electrical conductivity is an important property that defines its deliverable power since the power is inversely proportional to the equivalent series resistance $\left(R_{\mathrm{ES}}\right)$. Activated 
carbons are materials derived from carbonaceous materials that can be carbonized to generate many pores between the carbon atoms, therefore exhibits disordered microstructure (turbostratic structure). In general, a graphitic structure enhances the electrical conductivity of the carbon materials. The microstructure of the activated carbon can be investigated by Raman spectroscopy. Three featured bands are generally observed in Raman Spectrum, a D-band $\left(1358 \mathrm{~cm}^{-1}\right)$ corresponding to the structural defects or disordered structure in the carbon material, a G-band $\left(1567 \mathrm{~cm}^{-1}\right)$ associated to the $\mathrm{E}_{2 \mathrm{~g}}$ vibration mode of $2 \mathrm{D}$ graphitic and explained the crystallinity of the carbon material, and a 2D-band $\left(2715 \mathrm{~cm}^{-1}\right)$ characteristic band of graphitic carbon material. The ratio of the intensity ID/IG measures the degree of structural disorder respect to the graphitic structure. The works of G. Li et al. [68], L. Wang et al. [59], and Fan et al. [69] show the strong relationship between the ratio ID/IG and $\mathrm{R}_{\mathrm{ES}}$. As shown in Table 3, the equivalence series resistance increases with the increasing of the structural defects (disordered), and thereby reduces the deliverable power of the EDLC. The synthesis of activated carbon with high surface area by introducing more defects (porous structure) in the carbon materials enhances the capacitance but also increases the equivalent series resistance thereby decreases the power density dramatically. Gao et al. [70] synthesized porous carbon using Enteromorphaprolifera ocean biomass as carbon precursor and $\mathrm{KOH}$ as an activating agent at various mass ratio $(\mathrm{KOH} /$ precursor $=3,2,1$ and 0.5$)$. Their study of the microstructure of the prepared samples shows that the ratio ID/IG increases with the increase of the mass of the activating agent. Similar results were observed in the work of Fei et al. [8] using sakura as carbon precursor and $\mathrm{KOH}$ as activating agent. Hence, the mass ratio of the activating agent with precursor is an important parameter that affects the activated microstructure.

Table 2. Electric double-layer capacitors (EDLCs) capacitance dependence on electrodes porous texture [66].

\begin{tabular}{ccccc}
\hline $\begin{array}{c}V_{\text {micropores }} \\
{\left[\mathbf{c m}^{3} / \mathbf{g}\right]}\end{array}$ & $\begin{array}{c}V_{\text {mesopores }}+V_{\text {macropores }} \\
{\left[\mathbf{c m}^{3} / \mathbf{g}\right]}\end{array}$ & $\begin{array}{c}\text { Specific } \\
\text { Surface Area }\left[\mathbf{m}^{2} / \mathbf{g}\right]\end{array}$ & $\begin{array}{c}\text { Capacitance } \\
{[\mathbf{F} / \mathbf{g}]}\end{array}$ & ERS $(\Omega)$ \\
\hline 0.20 & 0.02 & 400 & 14.0 & 8.3 \\
0.57 & 0.06 & 1123 & 29.2 & 16.7 \\
0.71 & 0.1 & 1412 & 29.6 & 25.0 \\
1.27 & 0.13 & 2470 & 41.8 & - \\
1.24 & 0.08 & 2400 & 42.0 & - \\
1.25 & 0.11 & 2450 & 42.1 & - \\
1.25 & 1.13 & 2454 & 42.3 & 83.3 \\
1.28 & 0.18 & 2759 & 43.0 & 166,6 \\
1.39 & 0.22 & 2906 & 44.0 & 187.5 \\
\hline
\end{tabular}

Table 3. Variation in ESR of EDLC cells with the change in structural disorder degree (ID/IG) of activated carbon materials.

\begin{tabular}{ccc}
\hline Equivalent Serie Resistance $(\Omega)$ & Structural Disorder Degree (ID/IG) & Ref. \\
\hline 1.604 & 0.932 & \\
1.435 & 0.929 & [68] \\
1.108 & 0.921 & \\
0.952 & 0.915 & \\
0.809 & 0.921 & {$[59]$} \\
0.77 & 1.04 & \\
0.65 & 0.97 & \\
0.61 & 0.92 & {$[70]$} \\
0.38 & 0.9 & \\
\hline 0.73 & 1.42 & 1.11 \\
\hline 0.58 & &
\end{tabular}




\subsection{EDLCs Electrodes Performance Improvement by Heteroatoms Doping}

Various techniques have been proposed in the literature for the improvement of EDLCs' performance by researchers. Heteroatoms doping have mostly used as the best approach to enhance the EDLCs electrodes performance. It has been reported that the heteroatoms' doping by the introduction of hydrophilic species into the carbon matrix greatly improved the electrodes wettability, thereby improved the capacitance performance [71]. Furthermore, heteroatom doping improves the specific capacitance through the additional faradaic reaction between the heteroatoms species on the electrodes active surface and the electrolyte. Taeri Kwon et al. [72] synthesized two electrodes material based on N-, and Bdoped porous carbon with uniform mesopores diameter and investigated the performance of prepared electrodes in both organic and aqueous electrolyte. Their results proved that the occurrence of pseudo-capacitance is the main factor that must be taken into account in the enhancement of the capacitance by $\mathrm{N}$ - or B-doping in both organic and aqueous electrolyte. The pseudo-capacitance effect induced by N-, O-doped activated carbon has also been reported by Liu Wan et al. [59]. Liu Wan et al. [59] prepared Nitrogen-Enriched Hierarchically Porous Carbons Prepared from Polybenzoxazine and concluded that the largest specific capacitance of $641.6 \mathrm{~F} / \mathrm{g}$ at a current density of $1 \mathrm{~A} / \mathrm{g}$ in a $6 \mathrm{~mol} / \mathrm{L} \mathrm{KOH}$ aqueous electrolyte is ascribed to the great pseudo-capacitance introduced by active N-6, $\mathrm{N}-5$, O-II, and O-III functionalities owing by $\mathrm{N}-$, O-doped. Recently, researchers have devoted much effort to enhance the specific capacitance by introducing heteroatoms $(\mathrm{B}, \mathrm{N}, \mathrm{O}$, $\mathrm{P}$, and $\mathrm{S}$ ) in the carbon matrix. Figure 6 shows an illustration of $\mathrm{N-}, \mathrm{P}-$, and $\mathrm{S}$-doping route in carbon matrix via post-treatment route proposed by Hasegawa et al. [73], three doping sources are used for Nitrogen, Phosphorus and sulphur-doping: urea, Sodium amide/ Ammonium chloride $\left(\mathrm{NaNH}_{2} / \mathrm{NH}_{4} \mathrm{Cl}\right)$ mixture with Hexamethylenetetramine (HMTA), red phosphorus is used as a phosphorus source and sodium salts of sodium pyrosulfite $\left(\mathrm{Na}_{2} \mathrm{~S}_{2} \mathrm{O}_{5}\right)$ and Sodium pyrosulfate $\left(\mathrm{Na}_{2} \mathrm{~S}_{2} \mathrm{O}_{7}\right)$ for sulfurous source. The results of George et al. showed that $\mathrm{P}$-and S-doped carbon improved the specific capacitance in aqueous electrolyte compared to $\mathrm{N}$-doped carbon, and in the organic electrolyte S-doped exhibited the highest specific capacitance. The energy density is linearly proportional to both specific capacitance and the operating voltage window. Therefore, operating voltage is also a key factor to enhance the specific capacitance. George et al. reported that phosphorous doping not only increases the specific capacitance but also improves the operating voltage in aqueous electrolyte [73]. Deng et al. [74] synthesized electrodes based on N, O, P ternary doped porous carbon material for supercapacitor application. They pointed out that apart from used electrolytes, $P$ doped porous carbon can also extend the operating voltage window. In addition, doping with phosphorus and oxygen could improve the wettability of the electrodes, allowing the electrolyte ions to diffuse quickly inside the micropores. The doping with heteroatoms modifies the space charge layer density of the carbon materials by introducing more defects due to the difference in electronegativity of carbon material and used doping agent, thereby improving the conductivity of the material. The above observations demonstrate the effect of adding hydrophilic functional species to the porous carbon surface in terms of improving the energy density as well as the specific capacitance. However, Fang et al. [71] investigated the improvement of the capacitance by attachment of hydrophobic functional groups onto the activated carbon surface using sodium oleate as the surfactant in organic electrolyte. The results of Fang et al. showed that the wettability of the activated carbon material could be greatly improved in the organic electrolyte by surface modification with hydrophobic functional groups. It also results in decreasing the device's internal resistance and enhances the energy density, cyclic stability, as well as the specific capacitance.

In the following section, the combined effect of the porous carbon porous texture and the doped heteroatoms on the EDLCs performance is investigated. 


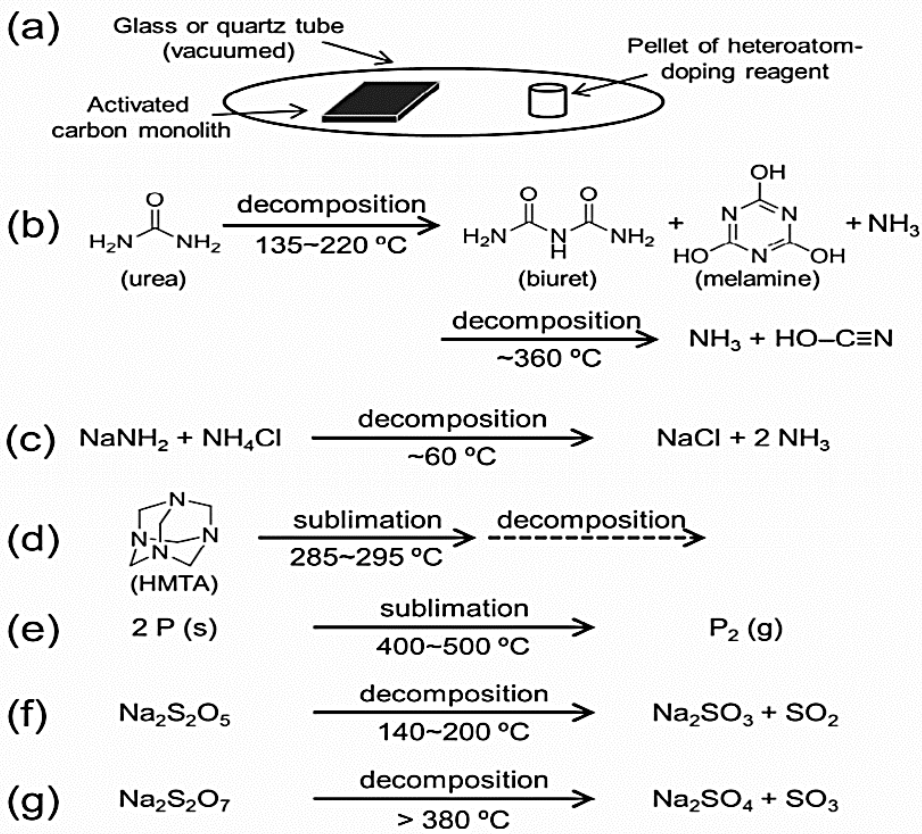

Figure 6. (a) Scheme illustrating hetero atom doping of carbons. (b-g) Reactions of the hetero-atom doping reagents at ambient pressure and high temperatures; (b) urea, (c) $\mathrm{NaNH}_{2} / \mathrm{NH}_{4} \mathrm{Cl}$ mixture, (d) HMTA, (e) red phosphorus, (f) $\mathrm{Na}_{2} \mathrm{~S}_{2} \mathrm{O}_{5}$ and (g) $\mathrm{Na}_{2} \mathrm{~S}_{2} \mathrm{O}_{7}$. Reproduced with permission from [74]. Copyright (2015) American Chemical Society.

\subsubsection{Effect of Heteroatoms Doping on EDLCs Cell Performance}

The heteroatom doping in carbon matrices introduces the contribution of pseudocapacitance, which is a capacitance generated by the ion transport induced by concentration or charge gradient between the carbon material and the electrolyte. On the contrary, doublelayer capacitance results from the ions electrostatically adsorbed at the electrode surface.

Therefore, according to the charge storage mechanism, two types of electrodes can be distinguished: (1) EDLC electrodes associated to a fast electrostatically storage of the charges at the electrode/electrolyte interfaces and (2) pseudocapacitor electrodes within charges are storage through a faradic reaction at the electrode/electrolyte interface. The incorporation of heteroatoms in activated carbon matrix can be achieved by either by treating carbon materials with reactive heteroatom sources in an inert atmosphere or by carbonizing high heteroatom-containing carbon precursors. The pseudo-capacitance effect in these cases is an only additional contribution to a dominant double-layer capacitance. The functional groups generate on the carbon surface undergo faradic redox reactions so contribute to pseudo-capacitance, thereby improving the overall capacitance. Hasegawa et al. [73] reported a new methodology to introduce heteroatoms in a carbon matrix via a post-treatment. In that process a carbon material is separately loaded with solid reactant heteroatoms sources in a vacuum-closed gases tube, followed by heating to obtain high, heteroatom-doped carbons with preserved porous morphology. Heteroatom doped carbon materials represent one of the most promising carbon materials for supercapacitor applications. Heteroatoms functionalities significantly increase the surface polarity of the carbon material and thereby improve the specific interactions between the electrodes active surface and the electrolyte ions via electrostatic forces [75]. The main advantage is to enhance the specific capacitance by improving the electrodes wettability, because of the increased number of hydrophilic polar sites and reducing the equivalent series resistance, by modification of the space-charge-layer capacitance [76].

\subsubsection{Effect of Heteroatoms Doping on the Wettability of Activated Carbon}

The wettability of a material is its surface property that determines how fast a liquid (water or solvent) will seep through the solid surface of the material. The better wettability 
of the electrodes facilitates the ions transport through the microspores, thereby enhances the electrochemical capacitance. Therefore, the wettability of the activated carbon material is one of the most important parameters that influences the electrodes charges storage capability. To enhance the material's wettability level, one should increase the surface of the usable electrode, which results in a possibility to accumulate more energy. Szubzda et al. [77] proposed a quantitative evaluation of the degree of wettability of porous carbon. One of the best ways to improve the wettability of the activated carbon in literature is the addition of surfactants for modifying the carbon material surface by means of functional groups with hydrophilic and hydrophobic properties, depending on types of the used electrolytes [77]. In this respect, heteroatom doping is the easier way to improve the wettability of the activated carbon. The heteroatoms species in the carbon matrix generates more hydrophilic polar sites; therefore, they improve the compatibility between the carbon surface and the electrolyte [76]. The hydrophilic species introduced by the heteroatoms, such as nitrogen, oxygen, or sulfur improves the wettability of carbon pore surface, thereby increasing the rate of charge accumulation of the electrode material. Figure 7 shows different sulfur, phosphorous and nitrogen species attached to activated carbon surface after post-treatment of the carbon precursor with reactive heteroatom sources.
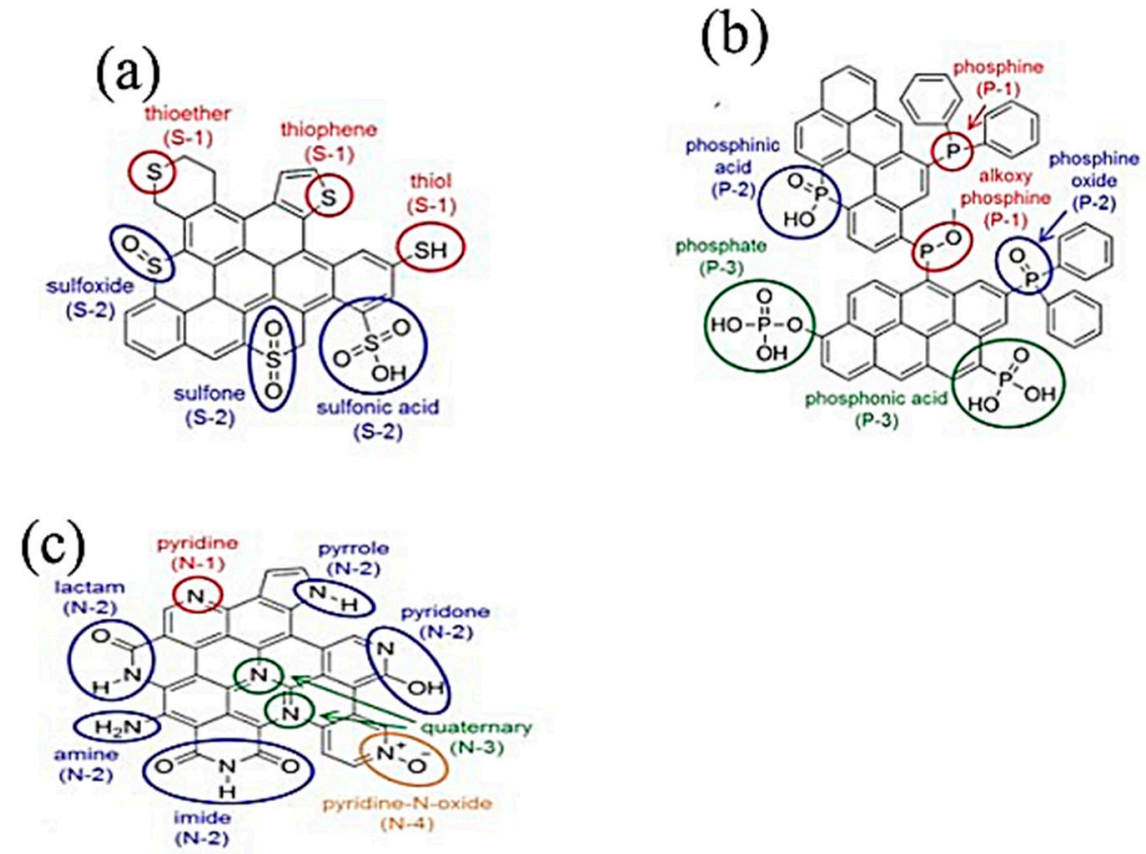

Figure 7. (a): Types of S-containing functional groups in a carbon matrix, (b): types of P-containing functional groups in a carbon matrix, (c): Types of N-containing functional groups in carbon matrix. Adapted with permission from [73]. Copyright (2015) American Chemical Society.

\subsubsection{Impact of Heteroatom Doping on the EDLCs Equivalent Series Resistance $\left(R_{\mathrm{ES}}\right)$}

Activated carbon suffers from low electrical conductivity with increasing porosity. The presence of microspores increases both the ohmic resistance of the material and the ions conductive pathways that limit accessibility to the electrode surface, and hence activated carbon with large specific surface area is unfavorable for the power performance of the supercapacitor [76]. Introducing heteroatom functionalities in the activated carbon matrices seems to be the most promising ways to decrease the equivalent series resistance, thereby improving the electrical conductivity of the carbon material. Activated carbon doped with heteroatoms could change the charge density of the activated carbon material by introducing more defects, thereby improving the electrical conductivity due to the difference in electronegativity. Seredychet al. [78] analyzed the role of the surface chemistry of the activated carbons on the performance of the electrodes based on carbon materials; they concluded that the conductivity of the carbons could be improved by doping nitrogen 
into the carbon skeleton [78]. Whon-Lee et al. [79] synthesized three electrodes based on carbon material: undoped-CS, low nitrogen doped-CS, and high nitrogen doped-CS, Their results proved that the equivalence series resistance decreases with increasing the nitrogen in the carbon matrix: undoped-CS $(1.44 \Omega)$, low nitrogen doped $\operatorname{CS}(1 \Omega)$, and high nitrogen-doped CS $(0.12 \Omega)$ [79]. Jianan Yi et al. synthesized lignocellulose-derived porous phosphorus-doped carbon as the electrode for supercapacitors application [80]. They found that phosphorous doping could decrease the equivalent series resistance $(2.03 \Omega)$, which enhances the electrical conductivity of the used precursor [81]. Weijiang $\mathrm{Si}$ et al. synthesized electrodes material based on N, S-doped activated carbon. The calculated value of the equivalent series resistance of all the samples is found to be very low (below $0.6 \Omega$ ), indicating good electrical conductivity [81,82]. Table 4 summarizes the comparison of the specific capacitance and equivalent series resistance for different heteroatoms used in different studies.

Table 4. Comparison of the specific capacitance and equivalent series resistance parameters of different heteroatoms-doping activated carbons in the literature.

\begin{tabular}{|c|c|c|c|c|c|c|}
\hline Precursor & Heteroatom-Doping & Activating Agent & Electrolyte & $\begin{array}{l}\text { ESR } \\
(\Omega)\end{array}$ & $\begin{array}{l}\text { Capacitance } \\
\text { (F/g) }\end{array}$ & Ref. \\
\hline Bio-wastebones & Nitrogen & $\mathrm{KOH}$ & $6 \mathrm{~mol} / \mathrm{L} \mathrm{KOH}$ & - & 302 & [83] \\
\hline Peony pollen & Nitrogen & $\mathrm{KOH}$ & $6 \mathrm{~mol} / \mathrm{L} \mathrm{KOH}$ & 0.59 & 209 & [84] \\
\hline Lignocellulose & Phosphorous & $\mathrm{ZnCL}_{2}$ & $6 \mathrm{~mol} / \mathrm{L} \mathrm{KOH}$ & 2.03 & 133 & [77] \\
\hline Fruit stones & Phosphorous & $\mathrm{H}_{3} \mathrm{PO}_{4}$ & $1 \mathrm{~mol} / \mathrm{L} \mathrm{H}_{2} \mathrm{SO}_{4}$ & - & 192 & [79] \\
\hline $\begin{array}{c}\text { Commercial activated } \\
\text { carbon }\end{array}$ & Sulfur & - & $6 \mathrm{~mol} / \mathrm{L} \mathrm{KOH}$ & - & 207 & [85] \\
\hline Olive stones & Sulfur & $\mathrm{KOH}$ & $1 \mathrm{~mol} / \mathrm{L} \mathrm{H}_{2} \mathrm{SO}_{4}$ & 0.32 & 325 & [86] \\
\hline Rape pollen & $\begin{array}{l}\text { Nitrogen/ } \\
\text { Sulfur }\end{array}$ & $\mathrm{ZnCL}_{2} / \mathrm{FeCl}_{3}$ & $6 \mathrm{~mol} / \mathrm{L} \mathrm{KOH}$ & 2.9 & 361 & [39] \\
\hline Ultrapure anthracite & Phosphorous & $\mathrm{KOH} / \mathrm{H}_{3} \mathrm{PO}_{4}$ & $\begin{array}{c}1 \mathrm{~mol} / \mathrm{L} \\
\mathrm{Et}_{4} \mathrm{NBF}_{4} / \mathrm{PC}\end{array}$ & 0.015 & 121 & [87] \\
\hline
\end{tabular}

\subsection{Recent Advancements in Activated Carbon Composites}

This section describes recent research efforts toward the improvement of the performance of activated carbon composite with either metal oxides or conducting polymers regarding the specific capacitance and the electrical conductivity for supercapacitors application. Activated carbon can form composites with metal oxides, such as $\mathrm{TiO}_{2}, \mathrm{ZnO}$, $\mathrm{MnO}_{2}$, and conducting polymers. Due to its good electrochemical properties, ruthenium oxide $\left(\mathrm{RuO}_{2}\right)$ still the best metal oxide widely used to enhance the supercapacitor specific capacitance through a fast faradic reaction at the electrodes/electrolyte interface. However, owing to both safety and expensive issue, cheap and eco-friendly metal oxides $\mathrm{TiO}_{2}, \mathrm{ZnO}$, $\mathrm{NiO}, \mathrm{MnO}_{2}$, and conducted polymers PANI, PPy became more attractive to be used in composite fabrication. Extensive research is devoted to the synthesis of activated carbon with large surface area composited with both metal oxides such as $\mathrm{TiO}_{2}, \mathrm{ZnO}, \mathrm{MnO}_{2}$, and conducting polymers PPy, PANI, which improves its charges accumulation capability. However, these composite materials do not achieve specific capacitance value close to that of $\mathrm{RuO}_{2}$. As discussed earlier, the increased specific surface area of the carbon material leads to an increase in the series connection of resistance, thereby reduced the electric conductivity of the material and its power density. Herein, recent strategies conducted in the improvement of the performance of activated carbon composited with metal oxides or conducting polymers are described.

\subsubsection{Activated Carbon/ $/ \mathrm{TiO}_{2}$ Composites}

$\mathrm{TiO}_{2}$ is a promising material for the synthesis of electrodes for supercapacitor owing to its high cyclic stability and good capacitance response. A quasi-rectangular shape of the $\mathrm{CV}$ curves is observed for electrodes based $\mathrm{TiO}_{2}$ material in the work of Devi et al. [88]; indicating that $\mathrm{TiO}_{2}$ electrode materials have a charge storage mechanism similar to that of the conventional electric double layer. However, the low capacitance value and the relatively 
low electrical conductivity $\left(>10^{-12} \mathrm{~S} \mathrm{~cm}^{-1}\right)$ due to the width energy band gap $3.2 \mathrm{eV}$, restrict their application to supercapacitors [89]. Recently, the works of Pazhamalai et al. [90] show that the design of electron rich $\mathrm{TiO}_{2}$ nanomaterials can provide hydrophilicity. Such a material used as electrode for supercapacitor can significantly enhance the electrochemical properties of the device. Therefore, it has been suggested that the synthesis of activated carbon $/ \mathrm{TiO}_{2}$ composite can enhance the activated carbon wettability by reducing the polarization of the activated carbon due to the electron rich $\mathrm{TiO}_{2}$ material, thereby enhancing its charge accumulation capacity. Sirengo et al. [91] studied the effect of the insertion of $\mathrm{TiO}_{2}$ nanomaterials into activated carbon matrix on the wettability of supercapacitors' electrodes prepared with the activated carbon $/ \mathrm{TiO}_{2}$ composite. The wettability of the electrode materials prepared using activated carbon $/ \mathrm{TiO}_{2}$ composite as active material was compared with reference electrodes prepared using pure activated carbon. Through Nyquist impedance diagrams of the synthesized electrodes, it was found that the electrodes prepared using activated carbon $/ \mathrm{TiO}_{2}$ composite exhibits the lower charge transfer resistance, which confirms the improvement of the wettability of the electrodes. Such a reduction of the interfacial polarization may be ascribed to the presence of $\mathrm{TiO}_{2}$ nanoparticles in the activated carbon matrix. However, they observed that the bulk resistance increased from $0.5 \Omega$ for the pure electrodes to $1.1 \Omega$ for the composite electrodes. The presence of $\mathrm{TiO}_{2}$ in the activated carbon matrix has almost doubled the internal resistance of the electrodes. Although activated carbon $/ \mathrm{TiO}_{2}$ composite can improve the charge storage capacity of the electrodes, thereby enhancing the energy density, can increase the internal resistance and short down power density. The electrochemical behavior of electrode materials using activated carbon $/ \mathrm{TiO}_{2}$ composite as active material has also been investigated by Shrivastav et al. [92]. As shown in Figure 8, the activated carbon / $\mathrm{TiO}_{2}$ composites CV curves showed better symmetric shape with reversible redox peaks, which are associated with faradic reactions, and higher value of the specific capacitance compared to the pure activated carbon. They ascribed the enhancement of the electrochemical performance to the combined effect of the activated carbon double-layer capacitance and the additional pseudo-capacitance due to the presence of the metal oxide $\mathrm{TiO}_{2}$ into the carbon matrix. The redox reaction can be described as follows:

$\mathrm{TiO}_{2}+2 \mathrm{H}_{2} \mathrm{O}+\mathrm{e}^{-} \rightleftharpoons \mathrm{Ti}(\mathrm{OH})_{3}+\mathrm{OH}^{-}$

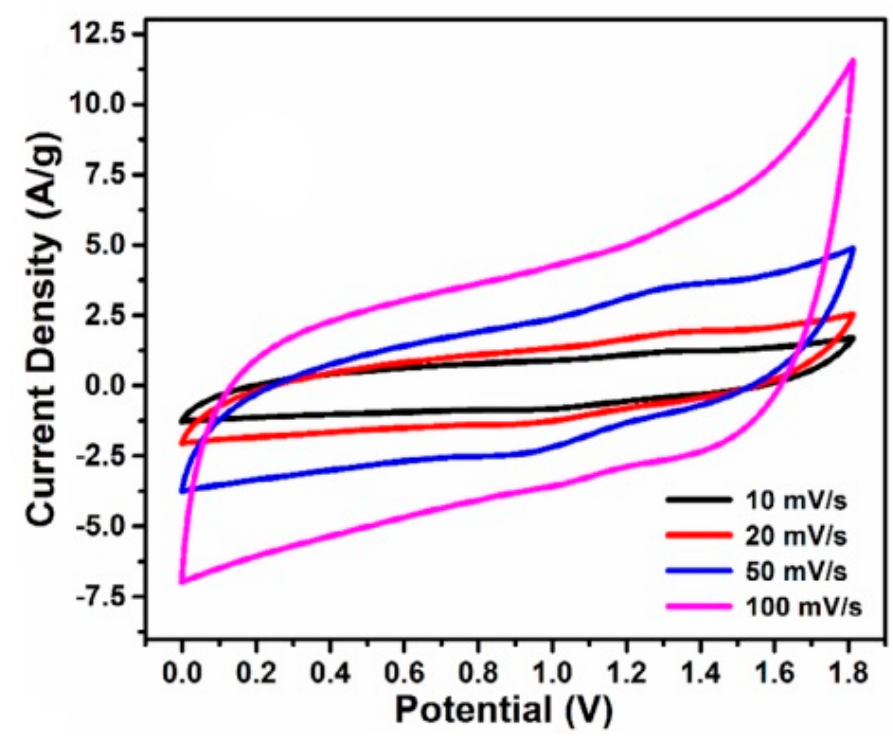

Figure 8. Cyclic voltammograms of $\mathrm{ACs} / \mathrm{TiO}_{2}$ composite electrodes at different scan rates and $1 \mathrm{M}$ $\mathrm{H}_{2} \mathrm{SO}_{4}$ electrolyte. Reprinted with permission from [92]. Copyright Wiley (2020).

\subsubsection{Activated Carbon/ZnO Composites}

Due to its good electrical and electrochemical properties, eco-friendly nature, and low cost, $\mathrm{ZnO}$ is regarded as one of the best materials for the synthesis of the electrode for su- 
percapacitor devices. However, it was found that supercapacitor electrodes based on $\mathrm{ZnO}$ materials have a short lifetime. To take full advantage of the good electrochemical activity of $\mathrm{ZnO}$ and the long-life cycle and porous textures of activated carbon in the improvement of the performance of supercapacitor, activated carbon/ $\mathrm{ZnO}$ composite materials have been investigated. Ibrahim at al. [2] prepared activated carbon/ZnO composite active material via hydrothermal treatment. The high value of the specific capacitance obtained $667 \mathrm{~F} / \mathrm{g}$ for the composite electrodes compared to $355 \mathrm{~F} / \mathrm{g}$ for electrodes fabricate using pure activated carbon in alkali electrolyte confirm the excellent electrochemical activity of $\mathrm{ZnO}$. They have also observed that the electrodes prepared using activated carbon/ZnO composite materials exhibits good cyclic stability. The composite electrodes retained $90 \%$ of their specific capacitance after 3000 cycles. The work of Ibrahim et al. demonstrates that the individual properties of $\mathrm{ZnO}$ (good electrochemical activity) and Activated carbon (good cyclic stability) can be combined to achieve high-performance supercapacitor electrodes. Similar results have been obtained by Wu et al. [93]. Wu et al. investigated the electrochemical properties of electrode materials based on activated carbon/ZnO composite with the goal to optimize the activated carbon/ZnO composite mass ratio for high-performance electrode materials for supercapacitor application. Better electrode performance was observed with $38.6 \mathrm{wt} \% \mathrm{ZnO}$ content and exhibited a specific capacitance of $720 \mathrm{~F} / \mathrm{g}$ at a current density of $1 \mathrm{~A} / \mathrm{g}$ and only $10 \%$ of the capacitance loss after 2000 cycles.

\subsubsection{Activated Carbon/ $\mathrm{MoS}_{2}$ Composites}

Nowadays, molybdenum-based materials are attracting the attention of researchers due to their abundant source, low price, and environmentally friendly properties. Among these Mo-based materials, $\mathrm{MoS}_{2}$ is largely used in the synthesis of electrode materials for energy storage devices. Similar in structure to graphene, $\mathrm{MoS}_{2}$ is a 2D structure, and its single layer form is called $1 \mathrm{H}-\mathrm{MoS}_{2}$, with a typical thickness of $0.65 \mathrm{~nm}$. Similar to $\mathrm{TiO}_{2}$ and $\mathrm{ZnO}$ monolayer, $\mathrm{MoS}_{2}$ is a semiconductor. It has been suggested that due to the relatively small direct energy band gap of $\mathrm{MoS}_{2}(1.8 \mathrm{eV})$ as compared to $\mathrm{TiO}_{2}(3.2 \mathrm{ev})$ and $\mathrm{ZnO}(3.4 \mathrm{eV})$, designing a suitable electrode microstructure based on $\mathrm{MoS}_{2}$ materialsshould provide high-performance supercapacitor device. Hence, extensive research work has been conducted to synthesize appropriate electrode microstructures based on $\mathrm{MoS}_{2}$ nanomaterials that can enable high-performance supercapacitor. However, due to it poor electronic conductivity and poor rate performance, the energy/power density of $\mathrm{MoS}_{2}$ supercapacitor reported until now are not satisfactory compared to commsercial supercapacitors devices Heba et al. [94]. To address the poor-rate performance issue, the activated carbon $/ \mathrm{MoS}_{2}$ composite has been synthesized. Sangeetha et al. [95] prepared supercapacitors electrodes based on activated carbon/ $\mathrm{MoS}_{2}$ composite and studied the electrochemical properties of the as-prepared electrode using $0.5 \mathrm{M} \mathrm{H}_{2} \mathrm{SO}_{4}$ electrolyte. The high value of the bulk resistance $\left(87 \Omega\right.$ ) shows the insertion of $\mathrm{MoS}_{2}$ in the carbon matrix increased the internal resistance of the prepared material, which is unfavorablefor obtaining high power density. The relatively low interfacial resistance $(6 \Omega)$ may be ascribed to the sulfur atoms attached at the interface electrode/electrolyte, which reduced the interfacial polarization of the electrodes, thereby improving its wettability. Due to its good wettability high specific capacitance was achieved $288 \mathrm{~F} / \mathrm{g}$. Interestingly, the composite active material has improved the rate performance of the prepared electrode only $21 \%$ of capacitance loss after 5000 cycles. The improvement in the rate performance was also observed in the work of Wang et al. [96], and the prepared composite electrode exhibited only $19.2 \%$ of capacitance loss after 10,000 cycles.

\subsubsection{Activated Carbon $/ \mathrm{MnO}_{2}$ Composite}

Manganese oxides $\left(\mathrm{MnO}_{2)}\right.$-based materials, owing to their high theoretical specific capacitance value about $1370 \mathrm{~F} / \mathrm{g}$, low cost, high abundance, environmentally friendly nature, good electrochemical activity leading to low corrosion in aqueous electrolyte, and good thermal stability, have been extensively investigated as electrode materials for 
supercapacitors [97]. Two mechanisms have been proposed in the literature to explain the $\mathrm{MnO}_{2}$ energy storage behavior.

Primarily, energy storage can occur by the intercalation of ions (hydrogen or metal cations as sodium, lithium, potassium), in the bulk of the material under electrochemical reduction and subsequent deintercalation under anodic electrochemical process. Furthermore, energy storage can depend on metal cations adsorption at the surface of $\mathrm{MnO}_{2}$ electrode. The charge storage mechanisms involve electrochemical reduction of $\mathrm{MnO}_{2}$ to $\mathrm{MnOOH}$ and the forward oxidation as follows:

$$
\begin{gathered}
\mathrm{MnO}_{2}+\mathrm{H}^{+}\left(\mathrm{C}^{+}\right)+\mathrm{e}^{-} \rightarrow \mathrm{MnOOH}(\mathrm{MnOO}-\mathrm{C}) \\
\left(\mathrm{MnO}_{2}\right)_{\text {surface }}+\mathrm{C}^{+}+\mathrm{e}^{-} \rightarrow\left(\mathrm{MnO}_{2}-\mathrm{C}^{+}\right)_{\text {surface }}
\end{gathered}
$$

The poor conductivity of $\mathrm{MnO}$-based materials and its deteriorated volume expansion currently limits its direct application in supercapacitor applications. In an attempt to enhance the performance of electrodes based on of $\mathrm{MnO}_{2}$ materials, activated carbon is found to be the best material to compound with $\mathrm{MnO}_{2}$ in order to stabilize the electrode microstructure and avoid deterioration volume expansion. Pravin et al. [98] investigated the synergetic effect of activated carbon porous texture and the good electrochemical behavior of $\mathrm{MnO}_{2}$ nanoparticles in improving supercapacitor performance. They synthesized activated carbon $/ \mathrm{MnO}_{2}$ composite material, and the as-prepared electrodes achieved a specific capacitance of $136 \mathrm{~F} / \mathrm{g}$ in the two-electrode system. The performance of the electrodes was further improved by Nitrogen doping and obtained high specific capacitance of $424 \mathrm{~F} / \mathrm{g}$. The improvement in the specific capacitance was ascribed to the fast faradic reaction at the interface electrode/electrolyte due to the presence of Nitrogen species and $\mathrm{MnO}_{2}$ nanoparticles attached at the interface of the active material. High-performance electrode materials have also been synthesized by Choi et al. [99] using activated carbon $/ \mathrm{MnO}_{2}$ as the active material. They prepared electrodes for supercapacitor using activated carbon/ $/ \mathrm{MnO}_{2}$ composite and compared the electrochemical performance of the as-prepared electrodes to that of electrodes fabricated using pure activated carbon. As compared to the electrodes prepared using pure activated carbon, it found that the composite electrode shows a relatively small BET surface area, which indicated that $\mathrm{MnO}_{2}$ nanoparticles block some micropores thereby reducing the specific surface area of the electrodes. However, the composite electrodes exhibit outstanding capacitance retention $99.7 \%$ after 5000 cycles and good specific capacitance $60 \mathrm{~F} / \mathrm{g}$.

\subsubsection{Activated Carbon/PANI Composites}

Polyaniline with high electrical conductivity can be synthesized with easy chemical methods. Electrodes based on Polyaniline with a specific capacitance value of up to a thousand farads per gram have been reported in the literature [100]. The high capacitance value achieved may be explained by the combination of the good electrical conductivity and the superior electrochemical activity of PANI based electrode materials. However, the specific capacitance achieved until now remains much lower than that of its theoretical capacitance value and the poor cyclic stability due to the swelling/shrinkage changes during the mass transport process hindering their practical application. We are expected that due to the high theoretical specific capacitance of PANI and the good mechanical property of activated carbon, electrode material based on activated carbon/PANI composite will exhibit superior performance compared to available supercapacitor electrodes in market. Tremendous efforts have been made to innovative synthesis materials based on activated carbon/PANI composites, that can enable low-cost supercapacitors with improving performance compared to current technology. Recently, Acharya et al. [101] have reported high-performance supercapacitor electrodes prepared using activated carbon/PANI composite as an active material. The prepared supercapacitor exhibits an energy density of $60.8 \mathrm{Wh} / \mathrm{kg}$ in organic electrolyte. Moreover, the prepared composite material using activated carbon stable matrix significantly slow down the mechanical degradation of the prepared electrodes, about $77 \%$ 
of capacitance retention after 5000 cycles. Similar outstanding results have been achieved in the work of Chonat et al. [102], who synthesized ternary doped Polyaniline/activated carbon composite material for supercapacitor application. Supercapacitor electrode materials obtained by combining ternary doped Polyaniline (PANI) with Cetyl Trimethyl Ammonium Bromide surfactant wrapped environmentally friendly activated carbon (AC) demonstrating outstanding electrochemical properties. In Figure 9 the ciclovoltammetric behavior of the material is reported at various potential scan rates. The CV curve is not influenced by the san rate, indicating the good power property and reversibility of the half-electrochemical reactions. The curves also show both EDLC and pseudo-capacitance properties because the increase of the area under the curve with increasing the scan rate and the permanence of the same reduction and oxidation peaks. High specific capacitance of $1250 \mathrm{~F} / \mathrm{g}$ with good cyclical stability (87\% capability following 1000 cycles) are obtained.

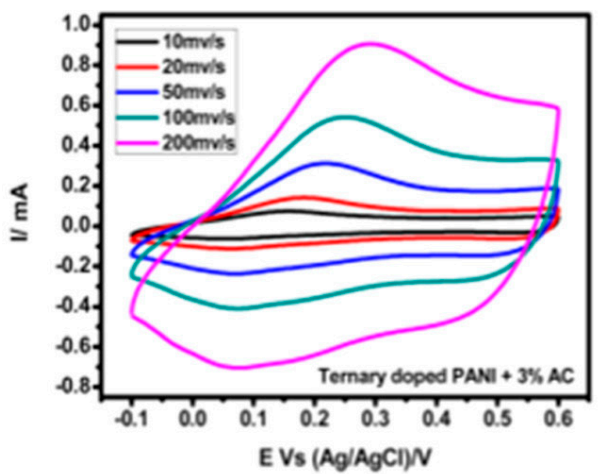

(a)

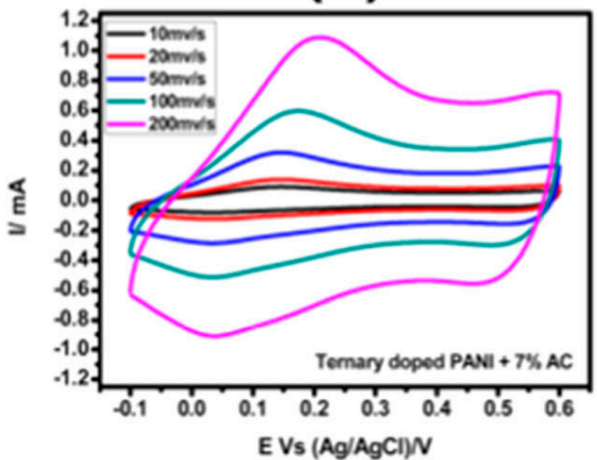

(c)

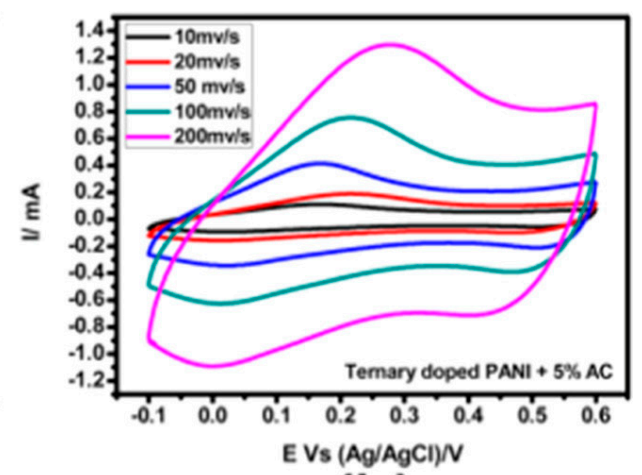

(b)

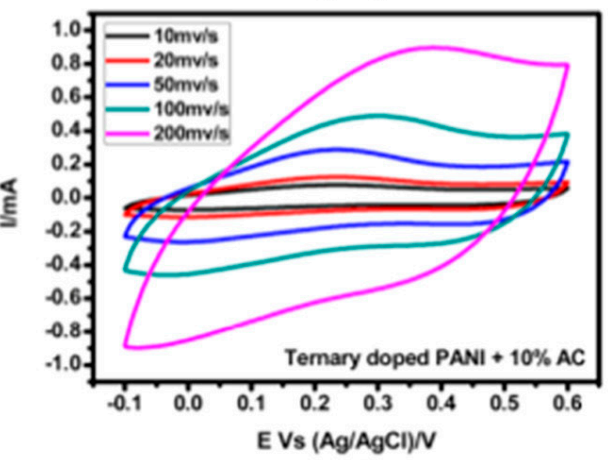

(d)

Figure 9. Electrochemical cyclic voltammetry (CV) curves of ternary doped PANI-AC composites at different scan rates and AC percentages (a) 3\%; (b) 5\%; (c) 7\%; (d) 10\%. Reprinted with permission from [102]. Copyright (2020) American Chemical Society.

\subsection{Porous Carbon Aerogels}

Carbon aerogels (CAGs) are three-dimensional materials with rare three-dimensional nanostructure and high conductivity that can be modulated to obtain tailored electrodes for supercapacitor requirements. CAGs are synthesized by the carbonization of polymeric organic aerogels [103], including resorcinol formaldehyde resin (RF-AG) [104], lignin [105], cellulose [106], chitosan [107], kapok fibers [108], polyimide gel [109], mphenylenediamine [110]. Due to their tunable 3-D hierarchical morphology with high surface area and their good conductivity, carbon aerogels are regarded as a promising carbon material for energy storage devices. Hierarchically structured porous carbon aerogel materials with a high specific surface area were synthesized and investigated as electrode materials for high performance supercapacitors. Yang et al. [104] carried out a comparative study on the electrochemical performances of electrode materials based on carbon aerogel 
and commercial activated carbon. The synthesized carbon aerogels exhibited both superior energy storage capacity and excellent conductivity compared to commercial activated carbon. The superior electrochemical performance of carbon aerogels over commercial activated carbon has been attributed to three main factors, including the hierarchical porous texture, the relatively large specific surface area, and the good electrical conductivity of the prepared carbon aerogel. The surface chemistry of the carbon aerogel can be further modified to increase the storage capacity of the prepared materials. Wu et al. [107] prepared carbon aerogels using chitosan precursor and subjecting it to a carbonization/activation process. Phosphoric acid and potassium hydroxide were used as both activating agent and heteroatom-source ( $\mathrm{P}$ and $\mathrm{K}$, respectively). A comparative study on the electrochemical activity of such electrodes is reported in Figure 10. It can be observed that carbon aerogel electrodes modified via heteroatoms doping provide enhanced electrical properties and energy storage capability with respect to pristine CAG electrode. Although carbon aerogel has better electrochemical performance compared to activated carbon materials, its low density $\left(<500 \mathrm{mg} / \mathrm{cm}^{3}\right)$ limits the achievable volumetric energy density. Improving the density of the carbon aerogel is a critical problem, which need to be resolved and allow their current application in the EDLCs industry.
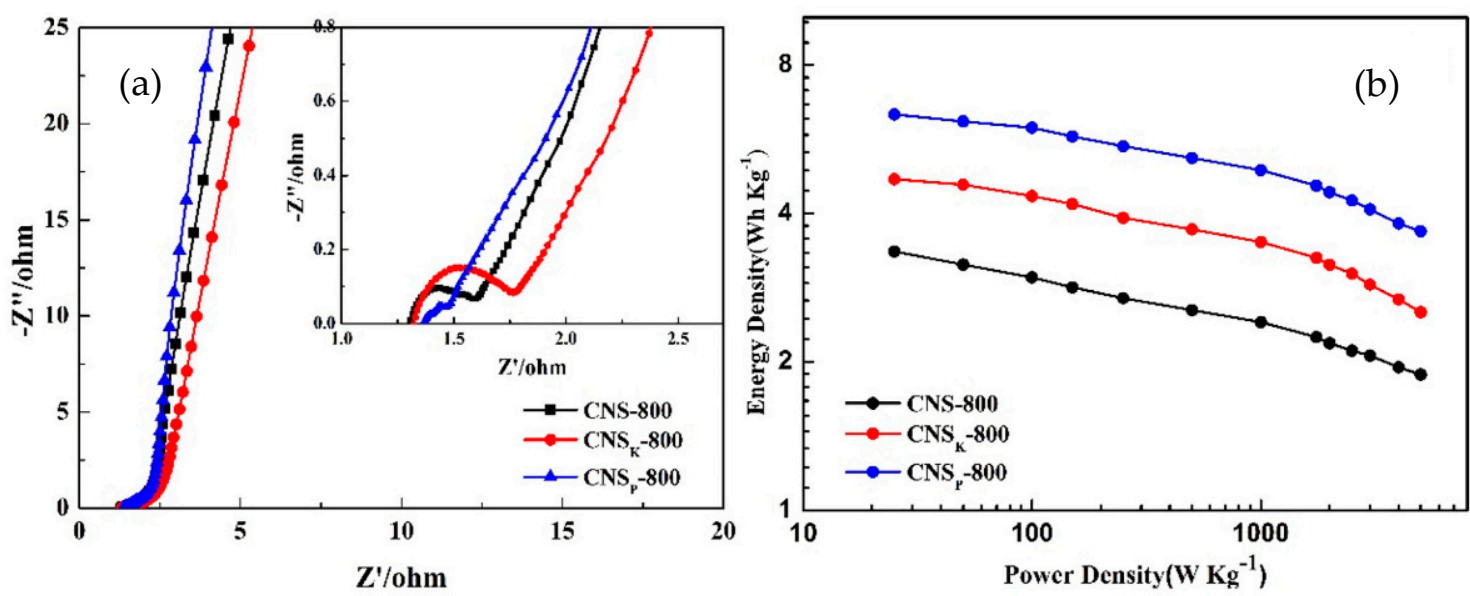

Figure 10. Electrochemical performance of carbon aerogel without chemical activation (CNS-800), with activation of potassium hydroxyl (CNSK-800) and activation of phosphorus (CNSP-800) in a two-electrode system in $1 \mathrm{M} \mathrm{H}_{2} \mathrm{SO}_{4}$ : $\mathrm{Nyquist}$ graphs (a), Ragone graphs (b). Reprinted from [107] with permission from Elsevier.

\subsection{Carbide-Derived Carbons}

Carbide-derived carbon is produced by extracting metals from metal carbides such as boron carbide $\left(\mathrm{B}_{4} \mathrm{C}\right)$, silicon carbide $(\mathrm{SiC})$, and titanium carbide $(\mathrm{TiC})$ via different techniques, including treatments in supercritical water or halogens as well as vacuum decomposition. Thus, metal carbides were subjected to a heat treatment between 700 and $1000{ }^{\circ} \mathrm{C}$ under chlorine gas flows, to etch metal atoms from various carbides and to form a highly porous carbon material with a high specific surface area $\left(2700 \mathrm{~m}^{2} / \mathrm{g}\right)$ higher than that of the theoretical specific area of graphite $\left(2630 \mathrm{~m}^{2} / \mathrm{g}\right)$ [111]. Moreover, the key advantage of the carbide-derived carbon system is the capability to precisely control the pore size in the micro (0.5-2 $\mathrm{nm})$ and meso ( $>2 \mathrm{~nm})$ dimensions [112]. Tallo et al. [113] demonstrated that the synthesis temperature and the used chlorine gas are two important factors, which control the electrical property and the energy storage capacity of the prepared material. In their work, micro- and mesoporous carbide-derived carbons (CFCs) are synthesized from $\mathrm{TiC}$ powder via a gas-phase reaction using $\mathrm{HCl}$ and $\mathrm{Cl}_{2}$ within the temperature range of $700-1100{ }^{\circ} \mathrm{C}$. Also, the synthesized materials were investigated as electrode materials for supercapacitor application. The effect of the synthesis temperature on the electrical property as well as the energy storage capacity was carried out through galvanostatic 
charge/discharge technique. The increase of the synthesis temperature reduced the discharge time thereby decreasing the charge storage capability of the prepared materials.

\section{Conclusions}

This review demonstrates that activated carbon with its high porous texture and suitable microstructure is essential to improve EDLCs' performance. A lot of progress has been made in understanding the electrochemical properties of EDLCs electrodes based on activated carbon materials. The surface chemistry of the activated carbon can be modified by introduction of heteroatoms (N, O, P, S, etc.) via (i) carbonization of heteroatom-enriched compounds, (ii) post-treatment of carbons with reactive heteroatom sources. The introduction of heteroatoms species in the carbon matrix generates more hydrophilic polar sites, which improve the wettability of the electrodes based on activated carbon materials, thereby facilitating the ions transport through the microspores. Activated carbon, due to its high microstructure disorder, has relatively poor conductivity. It has been proven that activated carbon doped with heteroatoms could change the charge density of the activated carbon material and enhanced the electrical conductivity by decreasing the equivalent series resistance of the cell. It is also observed that activated carbon composited with oxides $\mathrm{TiO}_{2}, \mathrm{ZnO}, \mathrm{NiO}, \mathrm{MnO}_{2}$, and conducted polymers PANI, PPy can significantly improve the efficiency of EDLCs. The decrease of the polarization of the carbon materials through the introduction of nano-size metals oxide in the activated carbon matrix and the pseudo-capacitance generate by either metal oxides or conducting polymers during the electrochemical process may the main factors that enhance the performance of the composite electrode.

Author Contributions: Conceptualization, Y.K. and M.G.; methodology, K.D.-S.; validation, S.P., A.K. and P.B.; formal analysis, K.D.-S., V.S.; investigation, M.G.; resources, Y.K.; data curation, P.B.; writing—original draft preparation, K.D.-S.; writing—review and editing, M.G., P.B.; visualization, P.B.; supervision, M.G.; project administration, A.K.; funding acquisition, Y.K. All authors have read and agreed to the published version of the manuscript.

Funding: This research received no external funding.

Acknowledgments: Y. Kumar acknowledges the financial support received from the Science and Engineering Research Board (SERB), Department of Science and Technology, Government of India (sanction no. ECR/2016/001871) under the scheme Early Career Research Award.

Conflicts of Interest: The authors declare no conflict of interest.

\section{References}

1. Yadav, N.; Yadav, N.; Hashmi, S. Ionic liquidincorporated, redox-active blendpolymerelectrolyte for high energydensity quasisolid-state carbonsupercapacitor. J. Power Sources 2020, 451, 227771. [CrossRef]

2. Mohamed, I.M.; Yasin, A.S.; Liu, C. Synthesis, surface characterization and electrochemical performance of ZnO @ activatedcarbon as a supercapacitorelectrodematerial in acidic and alkalineelectrolytes. Ceram. Int. 2020, 46, 3912-3920. [CrossRef]

3. Yadav, M.S.; Singh, N.; Kumar, A. Synthesis and characterization of zinc oxide nanoparticles and activatedcharcoalbasednanocomposite for supercapacitorelectrode application. J. Mater. Sci. Mater. Electron. 2018, 29, 6853-6869. [CrossRef]

4. Fang, Z.; Wang, J.; Wu, H.; Li, Q.; Fan, S.; Wang, J. Progress and challenges of flexible lithium ion batteries. J. Power Sources 2020, 454, 227932. [CrossRef]

5. Pang, X.; Zhou, T.; Jiang, Q.; Kumar, P.; Geng, S.; Jia, M.; Zhou, J.; Liu, B.; Qin, H. PorousGraphitic Carbon Fibers for FastChargingSupercapacitor Applications. Energy Technol. 2020, 8. [CrossRef]

6. Chunyi, Z.; Liming, D. Flexible Energy Conversion and Storage Devices; Willey-VCH: Weinheim, Germany, 2018.

7. Wang, J.; Zhang, X.; Li, Z.; Ma, Y.; Ma, L. Recent progress of biomass-derived carbon materials for supercapacitors. J. Power Sources 2020, 451, 227794. [CrossRef]

8. Ma, F.; Ding, S.; Ren, H.; Liu, Y. Sakura-based activated carbon preparation and its performance in supercapacitor applications. RSC Adv. 2019, 9, 2474-2483. [CrossRef]

9. Li, Y.; Zhang, D.; Zhang, Y.; He, J.; Wang, Y.; Wang, K.; Xu, Y.; Li, H.; Wang, Y. Biomass-derived microporous carbon with large micropore size for high-performance supercapacitors. J. Power Sources 2020, 448. [CrossRef]

10. Karnan, M.; Raj, A.G.K.; Subramani, K.; Santhoshkumar, S.; Sathish, M. The fascinating supercapacitive performance of activated carbon electrodes with enhanced energy density in multifarious electrolytes. Sustain. Energy Fuels 2020, 4, 3029-3041. [CrossRef] 
11. Available online: https://chem.libretexts.org/Bookshelves/Analytical_Chemistry/Book\%3A_Physical_Methods_in_Chemistry_ and_Nano_Science_(Barron)/02\%3A_Physical_and_Thermal_Analysis/2.07\%3A_Electrochemistry (accessed on 16 February 2021).

12. Kim, B.K.; Sy, S.; Yu, A.; Zhang, J. Handbook of Clean Energy Systems; Yan, J., Ed.; John Wiley \& Sons, Ltd.: Chichester, UK, 2015.

13. Mei, B.-A.; Munteshari, O.; Lau, J.; Dunn, B.; Pilon, L. Physical Interpretations of Nyquist Plots for EDLC Electrodes and Devices. J. Phys. Chem. C 2018, 122, 194-206. [CrossRef]

14. Yu, H.; Tang, Q.; Wu, J.; Lin, Y.; Fan, L.; Huang, M.; Lin, J.; Li, Y.; Yu, F. Using eggshell membrane as a separator in supercapacitor. J. Power Sources 2012, 206, 463-468. [CrossRef]

15. Cheng, Q.; Tang, J.; Ma, J.; Zhang, H.; Shinya, N.; Qin, L.-C. Graphene and carbon nanotube composite electrodes for supercapacitors with ultra-high energy density. Phys. Chem. Chem. Phys. 2011, 13, 17615-17624. [CrossRef] [PubMed]

16. Harry, M.; Francisco, R.R. Activated Carbon; Elsevier Science: Amsterdam, The Netherlands, 2006.

17. Aktaş, Ö.; Çeçen, F. Effect of type of carbon activation on adsorption and its reversibility. J. Chem. Technol. Biotechnol. 2005, 81, 94-101. [CrossRef]

18. Suzuki, M. Adsorption Engineering; Elsevier: Amsterdam, The Netherlands, 1990.

19. Channiwala, S.; Parikh, P. A unified correlation for estimating HHV of solid, liquid and gaseous fuels. Fuel 2002, 81, 1051-1063. [CrossRef]

20. Mi, J.; Wang, X.-R.; Fan, R.-J.; Qu, W.-H.; Li, W.-C. Coconut-Shell-Based Porous Carbons with a Tunable Micro/Mesopore Ratio for High-Performance Supercapacitors. Energy Fuels 2012, 26, 5321-5329. [CrossRef]

21. Liu, W.; Mei, J.; Liu, G.; Kou, Q.; Yi, T.-F.; Xiao, S. Nitrogen-Doped Hierarchical Porous Carbon from Wheat Straw for Supercapacitors. ACS Sustain. Chem. Eng. 2018, 6, 11595-11605. [CrossRef]

22. He, X.; Ling, P.; Yu, M.; Wang, X.; Zhang, X.; Zheng, M. Rice husk-derived porous carbons with high capacitance by ZnCl2 activation for supercapacitors. Electrochim. Acta 2013, 105, 635-641. [CrossRef]

23. Rufford, T.E.; Hulicova-Jurcakova, D.; Khosla, K.; Zhu, Z.; Lu, G.Q. Microstructure and electrochemical double-layer capacitance of carbon electrodes prepared by zinc chloride activation of sugar cane bagasse. J. Power Sources 2010, 195, 912-918. [CrossRef]

24. Yang, C.-S.; Jang, Y.S.; Jeong, H.K. Bamboo-based activated carbon for supercapacitor applications. Curr. Appl. Phys. 2014, 14, 1616-1620. [CrossRef]

25. Cordero, T.; Marquez, F.; Rodriguez-Mirasol, J.; Rodriguez, J. Predicting heating values of lignocellulosics and carbonaceous materials from proximate analysis. Fuel 2001, 80, 1567-1571. [CrossRef]

26. Elmouwahidi, A.; Bailón-García, E.; Pérez-Cadenas, A.F.; Maldonado-Hódar, F.J.; Carrasco-Marín, F. Activated carbons from $\mathrm{KOH}$ and $\mathrm{H} 3 \mathrm{PO} 4$-activation of olive residues and its application as supercapacitor electrodes. Electrochim. Acta 2017, 229, 219-228. [CrossRef]

27. Jain, A.; Tripathi, S.K. Almond shell-based activated nanoporous carbon electrode for EDLCs. Ionics 2014, 21, 1391-1398. [CrossRef]

28. Boumanchar, I.; Charafeddine, K.; Chhiti, Y.; Alaoui, F.E.M.; Sahibed-Dine, A.; Bentiss, F.; Jama, C.; Bensitel, M. Biomass higher heating value prediction from ultimate analysis using multiple regression and genetic programming. Biomass-Convers. Biorefinery 2019, 9, 499-509. [CrossRef]

29. Li, X.; Xing, W.; Zhuo, S.; Zhou, J.; Li, F.; Qiao, S.-Z.; Lu, G.-Q. Preparation of capacitor's electrode from sunflower seed shell. Bioresour. Technol. 2011, 102, 1118-1123. [CrossRef]

30. Munir, S.; Daood, S.; Nimmo, W.; Cunliffe, A.; Gibbs, B. Thermal analysis and devolatilization kinetics of cotton stalk, sugar cane bagasse and shea meal under nitrogen and air atmospheres. Bioresour. Technol. 2009, 100, 1413-1418. [CrossRef]

31. Tian, X.; Ma, H.; Li, Z.; Yan, S.; Ma, L.; Yu, F.; Wang, G.; Guo, X.; Ma, Y.; Wong, C. Flute type micropores activated carbon from cotton stalk for high performance supercapacitors. J. Power Sources 2017, 359, 88-96. [CrossRef]

32. Bonelli, P.R. Slow Pyrolysis of Nutshells: Characterization of Derived Chars and of Process Kinetics. Energy Sources 2003, 25, 767-778. [CrossRef]

33. Wei, X.; Wan, S.; Jiang, X.; Wang, Z.; Gao, S. Peanut-Shell-like Porous Carbon from Nitrogen-Containing Poly-Nphenylethanolamine for High-Performance Supercapacitor. ACS Appl. Mater. Interfaces 2015, 7, 22238-22245. [CrossRef]

34. Jenkins, B.; Baxter, L.; Miles, T. Combustion properties of biomass. Fuel Process. Technol. 1998, 54, 17-46. [CrossRef]

35. Sudhan, N.; Subramani, K.; Karnan, M.; Ilayaraja, N.; Sathish, M. Biomass-Derived Activated Porous Carbon from Rice Straw for a High-Energy Symmetric Supercapacitor in Aqueous and Non-aqueous Electrolytes. Energy Fuels 2017, 31, 977-985. [CrossRef]

36. Yumak, T.; Yakaboylu, G.A.; Oginni, O.; Singh, K.; Ciftyurek, E.; Sabolsky, E.M. Comparison of the electrochemical properties of engineered switchgrass biomass-derived activated carbon-based EDLCs. Colloids Surf. A Physicochem. Eng. Asp. 2020, $586,124150$. [CrossRef]

37. Phiri, J.; Dou, J.; Vuorinen, T.; Gane, P.A.C.; Maloney, T.C. Highly Porous Willow Wood-Derived Activated Carbon for HighPerformance Supercapacitor Electrodes. ACS Omega 2019, 4, 18108-18117. [CrossRef] [PubMed]

38. Masiá, A.T.; Buhre, B.; Gupta, R.; Wall, T. Characterising ash of biomass and waste. Fuel Process. Technol. 2007, 88, 1071-1081. [CrossRef]

39. Wan, L.; Wei, W.; Xie, M.; Zhang, Y.; Li, X.; Xiao, R.; Chen, J.; Du, C. Nitrogen, sulfur co-doped hierarchically porous carbon from rape pollen as high-performance supercapacitor electrode. Electrochim. Acta 2019, 311, 72-82. [CrossRef] 
40. García, C.P.; Pizarro, C.; Lavín, A.G.; Bueno, J.L. Biomass proximate analysis using thermogravimetry. Bioresour. Technol. 2013, 139, 1-4. [CrossRef]

41. Xiangyu, Y.; Manjusri, M.; Stefano, G.; Amar, K.M. Preparation of an Electric Double Layer Capacitor (EDLC) Using MiscanthusDerived Biocarbon. ACS Sustain. Chem. Eng. 2018, 6, 318-324.

42. Lin, Y.; Chen, Z.; Yu, C.; Zhong, W. Heteroatom-Doped Sheet-Like and Hierarchical Porous Carbon Based on Natural Biomass Small Molecule Peach Gum for High-Performance Supercapacitors. ACS Sustain. Chem. Eng. 2019, 7, 3389-3403. [CrossRef]

43. Hu, C.-C.; Wang, C.-C.; Wu, F.-C.; Tseng, R.-L. Characterization of pistachio shell-derived carbons activated by a combination of $\mathrm{KOH}$ and $\mathrm{CO} 2$ for electric double-layer capacitors. Electrochimica Acta 2007, 52, 2498-2505. [CrossRef]

44. Vunain, E.; Kenneth, D.; Biswick, T. Synthesis and characterization of low-cost activated carbon prepared from Malawian baobab fruit shells by H3PO4 activation for removal of $\mathrm{Cu}(\mathrm{II})$ ions: Equilibrium and kinetics studies. Appl. Water Sci. 2017, 7, 4301-4319. [CrossRef]

45. Mohammed, N.; Mahamad, M.; Abbas, A.; Zaini, Z.; Akmar, Z. International Biodeterioration \& Biodegrada-tion. Struc. Func. Serv. Manag. 2015, 102, 274-280.

46. Sodtipinta, J.; Ieosakulrat, C.; Poonyayant, N.; Kidkhunthod, P.; Chanlek, N.; Amornsakchai, T.; Pakawatpanurut, P. Interconnected open-channel carbon nanosheets derived from pineapple leaf fiber as a sustainable active material for supercapacitors. Ind. Crop. Prod. 2017, 104, 13-20. [CrossRef]

47. Fernandes, E.R.K.; Marangoni, C.; Souza, O.; Sellin, N. Thermochemical characterization of banana leaves as a potential energy source. Energy Convers. Manag. 2013, 75, 603-608. [CrossRef]

48. Biswal, M.; Banerjee, A.; Deo, M.; Ogale, S. From dead leaves to high energy density supercapacitors. Energy Environ. Sci. 2013, 6, 1249-1259. [CrossRef]

49. Bello, O.S.; Adegoke, K.A.; Akinyunni, O.O. Preparation and characterization of a novel adsorbent from Moringa oleifera leaf. Appl. Water Sci. 2017, 7, 1295-1305. [CrossRef]

50. Cai, Y.; Luo, Y.; Xiao, Y.; Zhao, X.; Liang, Y.; Hu, H.; Dong, H.; Sun, L.; Liu, Y.; Zheng, M. Facile Synthesis of Three-Dimensional Heteroatom-Doped and Hierarchical Egg-Box-Like Carbons Derived from Moringa oleifera Branches for High-Performance Supercapacitors. ACS Appl. Mater. Interfaces 2016, 8, 33060-33071. [CrossRef]

51. Subramani, K.; Sudhan, N.; Karnan, M.; Sathish, M. Orange Peel Derived Activated Carbon for Fabrication of High-Energy and High-Rate Supercapacitors. ChemistrySelect 2017, 2, 11384-11392. [CrossRef]

52. Köseoğlu, E.; Akmil-Başar, C. Preparation, structural evaluation and adsorptive properties of activated carbon from agricultural waste biomass. Adv. Powder Technol. 2015, 26, 811-818. [CrossRef]

53. Lim, E.; Jo, C.; Lee, J. A mini review of designed mesoporous materials for energy-storage applications: From electric double-layer capacitors to hybrid supercapacitors. Nanoscale 2016, 8, 7827-7833. [CrossRef]

54. Chen, X.; Wu, K.; Gao, B.; Xiao, Q.; Kong, J.; Xiong, Q.; Peng, X.; Zhang, X.; Fu, J. Three-Dimensional Activated Carbon Recycled from Rotten Potatoes for High-performance Supercapacitors. Waste Biomass-Valorization 2015, 7, 551-557. [CrossRef]

55. Aman, T.; Kazi, A.A.; Sabri, M.U.; Bano, Q. Potato peels as solid waste for the removal of heavy metal copper(II) from waste water/industrial effluent. Colloids Surf. B Biointerfaces 2008, 63, 116-121. [CrossRef]

56. Elmouwahidi, A.; Zapata-Benabithe, Z.; Carrasco-Marín, F.; Moreno-Castilla, C. Activated carbons from KOH-activation of argan (Argania spinosa) seed shells as supercapacitor electrodes. Bioresour. Technol. 2012, 111, 185-190. [CrossRef]

57. Boujibar, O.; Ghosh, A.; Achak, O.; Chafik, T.; Ghamouss, F. A high energy storage supercapacitor based on nanoporous activated carbon electrode made from Argan shells with excellent ion transport in aqueous and non-aqueous electrolytes. J. Energy Storage 2019, 26, 100958. [CrossRef]

58. Lee, J.; Kim, J.; Hyeon, T. Recent Progress in the Synthesis of Porous Carbon Materials. Adv. Mater. 2006, 18, 2073-2094. [CrossRef]

59. Wan, L.; Wang, J.; Xie, L.; Sun, Y.; Li, K. Nitrogen-Enriched Hierarchically Porous Carbons Prepared from Polybenzoxazine for High-Performance Supercapacitors. ACS Appl. Mater. Interfaces 2014, 6, 15583-15596. [CrossRef]

60. Sun, L.; Tian, C.; Fu, Y.; Yang, Y.; Yin, J.; Wang, L.; Fu, H. Nitrogen-Doped Porous Graphitic Carbon as an Excellent Electrode Material for Advanced Supercapacitors. Chem. A Eur. J. 2014, 20, 564-574. [CrossRef]

61. Fang, B.; Wei, Y.-Z.; Kumagai, M. Modified carbon materials for high-rate EDLCs application. J. Power Sources 2006, 155, 487-491. [CrossRef]

62. Obreja, V.V.N. On the Performance of Supercapacitors with Electrodes Based on Carbon Nanotubes and Carbon Activated Material-A Review. Phys. E Low Dimens. Syst. Nanostruct. 2008, 40, 2596-2605. [CrossRef]

63. Ji, F.; Wang, L.; Yang, J.; Wu, X.; Li, M.; Jiang, S.; Lin, S.; Chen, Z. Highly compact, free-standing porous electrodes from polymer-derived nanoporous carbons for efficient electrochemical capacitive deionization. J. Mater. Chem. A 2019, 7, 1768-1778. [CrossRef]

64. Alaya, M.N.; Youssef, A.M.; Karman, M.; Abd El-AalA, H.E. Adsorption of Phenols onto Chemically-Activated Carbons Developed from Wild Cherry Stones. Carbon Sci. 2006, 7, 9-18.

65. Raymundo-Piñero, E.; Leroux, F.; Béguin, F. A High-Performance Carbon for Supercapacitors Obtained by Carbonization of a Seaweed Biopolymer. Adv. Mater. 2006, 18, 1877-1882. [CrossRef]

66. Qiao, W.; Yoon, S.-H.; Mochida, I. KOH Activation of Needle Coke to Develop Activated Carbons for High-Performance EDLC. Energy Fuels 2006, 20, 1680-1684. [CrossRef] 
67. Wang, M.-X.; Wang, C.-Y.; Chen, M.-M.; Wang, Y.-S.; Shi, Z.-Q.; Du, X.; Li, T.-Q.; Hu, Z.-J. Preparation of high-performance activated carbons for electric double layer capacitors by $\mathrm{KOH}$ activation of mesophase pitches. New Carbon Mater. 2010, 25, 285-290. [CrossRef]

68. Li, G.; Gao, X.; Wang, K.; Cheng, Z. Porous carbon nanospheres with high EDLC capacitance. Diam. Relat. Mater. 2018, 88, 12-17. [CrossRef]

69. Fan, Y.; Yang, X.; Zhu, B.; Liu, P.-F.; Lu, H.-T. Micro-mesoporous carbon spheres derived from carrageenan as electrode material for supercapacitors. J. Power Sources 2014, 268, 584-590. [CrossRef]

70. Gao, X.; Xing, W.; Zhou, J.; Wang, G.; Zhuo, S.; Liu, Z.; Xue, Q.; Yan, Z. Superior capacitive performance of active carbons derived from Enteromorpha prolifera. Electrochim. Acta 2014, 133, 459-466. [CrossRef]

71. Fang, B.; Binder, L. A Novel Carbon Electrode Material for Highly Improved EDLC Performance. J. Phys. Chem. B 2006, 110, 7877-7882. [CrossRef]

72. Kwon, T.; Nishihara, H.; Itoi, H.; Yang, Q.-H.; Kyotani, T. Enhancement Mechanism of Electrochemical Capacitance in Nitrogen/Boron-Doped Carbons with Uniform Straight Nanochannels. Langmuir 2009, 25, 11961-11968. [CrossRef] [PubMed]

73. Hasegawa, G.; Deguchi, T.; Kanamori, K.; Kobayashi, Y.; Kageyama, H.; Abe, T.; Nakanishi, K. High-Level Doping of Nitrogen, Phosphorus, and Sulfur into Activated Carbon Monoliths and Their Electrochemical Capacitances. Chem. Mater. 2015, 27, 4703-4712. [CrossRef]

74. Deng, Y.; Ji, Y.; Wu, H.; Chen, F. Enhanced electrochemical performance and high voltage window for supercapacitor based on multi-heteroatom modified porous carbon materials. Chem. Commun. 2018, 55, 1486-1489. [CrossRef] [PubMed]

75. Strelko, V.; Kuts, V.; Thrower, P. On the mechanism of possible influence of heteroatoms of nitrogen, boron and phosphorus in a carbon matrix on the catalytic activity of carbons in electron transfer reactions. Carbon 2000, 38, 1499-1503. [CrossRef]

76. Hulicova, D.; Kodama, M.; Hatori, H. Electrochemical Performance of Nitrogen-Enriched Carbons in Aqueous and Non-Aqueous Supercapacitors. Chem. Mater. 2006, 18, 2318-2326. [CrossRef]

77. Szubzda, B.; Szmaja, A.; Halama, A. Influence of structure and wettability of supercapacitor electrodes carbon materials on their electrochemical properties in water and organic solutions. Electrochim. Acta 2012, 86, 255-259. [CrossRef]

78. Seredych, M.; Hulicova-Jurcakova, D.; Lu, G.Q.; Bandosz, T.J. Surface functional groups of carbons and the effects of their chemical character, density and accessibility to ions on electrochemical performance. Carbon 2008, 46, 1475-1488. [CrossRef]

79. Lee, W.-H.; Moon, J.H. Monodispersed N-Doped Carbon Nanospheres for Supercapacitor Application. ACS Appl. Mater. Interfaces 2014, 6, 13968-13976. [CrossRef]

80. Yi, J.; Qing, Y.; Wu, C.; Zeng, Y.; Wu, Y.; Lu, X.; Tong, Y. Lignocellulose-derived porous phosphorus-doped carbon as advanced electrode for supercapacitors. J. Power Sources 2017, 351, 130-137. [CrossRef]

81. Si, W.; Zhou, J.; Zhang, S.; Li, S.; Xing, W.; Zhuo, S. Tunable N-doped or dual N, S-doped activated hydrothermal carbons derived from human hair and glucose for supercapacitor applications. Electrochim. Acta 2013, 107, 397-405. [CrossRef]

82. Hulicova-Jurcakova, D.; Puziy, A.M.; Poddubnaya, O.I.; Suárez-García, F.; Tascón, J.M.D.; Lu, G.Q. Highly Stable Performance of Supercapacitors from Phosphorus-Enriched Carbons. J. Am. Chem. Soc. 2009, 131, 5026-5027. [CrossRef] [PubMed]

83. Liu, Y.; An, Z.; Wu, M.; Yuan, A.; Zhao, H.; Zhang, J.; Xu, J. Peony pollen derived nitrogen-doped activated carbon for supercapacitor application. Chin. Chem. Lett. 2020, 31, 1644-1647. [CrossRef]

84. Niu, L.; Shen, C.; Yan, L.; Zhang, J.; Lin, Y.; Gong, Y.; Li, C.; Sun, C.Q.; Xu, S. Waste bones derived nitrogen-doped carbon with high micropore ratio towards supercapacitor applications. J. Colloid Interface Sci. 2019, 547, 92-101. [CrossRef]

85. He, Z.Q.; Chen, D.D.; Wang, M.; Li, C.X.; Chen, X.Y.; Zhang, Z.J. Sulfur modification of carbon materials as well as the redox additive of $\mathrm{Na} 2 \mathrm{~S}$ for largely improving capacitive performance of supercapacitors. J. Electroanal. Chem. 2020, 856, 113678. [CrossRef]

86. Elmouwahidi, A.; Castelo-Quibén, J.; Vivo-Vilches, J.F.; Pérez-Cadenas, A.F.; Maldonado-Hódar, F.J.; Carrasco-Marín, F. Activated carbons from agricultural waste solvothermally doped with sulphur as electrodes for supercapacitors. Chem. Eng. J. 2018, 334, 1835-1841. [CrossRef]

87. Ma, W.; Xie, L.; Dai, L.; Sun, G.; Chen, J.; Su, F.; Cao, Y.; Lei, H.; Kong, Q.; Chen, C.-M. Influence of phosphorus doping on surface chemistry and capacitive behaviors of porous carbon electrode. Electrochimica Acta 2018, 266, 420-430. [CrossRef]

88. Ojha, D.P.; Poudel, M.B.; Kim, H.J. Investigation of electrochemical performance of a high surface area mesoporous Mn doped $\mathrm{TiO}_{2}$ nanoparticle for a supercapacitor. Mater. Lett. 2020, 264, 127363. [CrossRef]

89. Charan, K.A.; Lakshmi, N.; Hussain, O.M.; Sreedhara, P.R. Electrospun $\mathrm{TiO}_{2}$ nanofiber electrodes for high performance supercapacitors. Mater. Res. Express 2020, 7, 015098.

90. Pazhamalai, P.; Krishnamoorthy, K.; Mariappan, V.K.; Kim, S.-J. Blue $\mathrm{TiO}_{2}$ nanosheets as a high-performance electrode material for supercapacitors. J. Colloid Interface Sci. 2019, 536, 62-70. [CrossRef] [PubMed]

91. Sirengo, K.; Jande, Y.; Kibona, T.; Hilonga, A.; Muiva, C.; King'Ondu, C.K. Fish bladder-based activated carbon $/ \mathrm{Co}_{3} \mathrm{O}_{4} / \mathrm{TiO}_{2}$ composite electrodes for supercapacitors. Mater. Chem. Phys. 2019, 232, 49-56. [CrossRef]

92. Shrivastav, V.; Sundriyal, S.; Kim, K.; Sinha, R.K.; Tiwari, U.K.; Deep, A. Metal-organic frameworks-derived titanium dioxidecarbon nanocomposite for supercapacitor applications. Int. J. Energy Res. 2020, 44, 6269-6284. [CrossRef]

93. Wu, G.; Song, Y.; Wan, J.; Zhang, C.; Yin, F. Synthesis of ultrafine ZnO nanoparticles supported on nitrogen-doped ordered hierarchically porous carbon for supercapacitor. J. Alloys Compd. 2019, 806, 464-470. [CrossRef] 
94. El Sharkawy, H.M.; Dhmees, A.S.; Tamman, A.; El Sabagh, S.; Aboushahba, R.; Allam, N.K. N-doped carbon quantum dots boost the electrochemical supercapacitive performance and cyclic stability of MoS2. J. Energy Storage 2020, 27, 101078. [CrossRef]

95. Sangeetha, P.; Selvakumari, T.M.; Selvasekarapandian, S.; Srikumar, S.R.; Manjuladevi, R.; Mahalakshmi, M. Preparation and characterization of biopolymer K-carrageenan with $\mathrm{MgCl} 2$ and its application to electrochemical devices. Ionics 2020, 26, 233-244. [CrossRef]

96. Wang, F.; Ma, J.; Zhou, K.; Li, X. MoS2/corncob-derived activated carbon for supercapacitor application. Mater. Chem. Phys. 2020, 244, 122215. [CrossRef]

97. Wang, X.; Wu, Y.; Song, X.; Dubal, D.P.; Zhao, X.; Zhang, D. Review on Carbon/Polyaniline Hybrids: Design and Synthesis for Supercapacitor. Molecules 2019, 24, 2263. [CrossRef] [PubMed]

98. Wadekar, P.H.; Khose, R.V.; Pethsangave, D.A.; Some, S. Waste-Derived Heteroatom-Doped Activated Carbon/Manganese Dioxide Trio-Composite for Supercapacitor Applications. Energy Technol. 2020, 8. [CrossRef]

99. Choi, J.R.; Lee, J.W.; Yang, G.; Heo, Y.-J.; Park, S.-J. Activated Carbon/ $\mathrm{MnO}_{2}$ Composites as Electrode for High Performance Supercapacitors. Catalysts 2020, 10, 256. [CrossRef]

100. Liu, P.; Yan, J.; Guang, Z.; Huang, Y.; Li, X.; Huang, W. Recent advancements of polyaniline-based nanocomposites for supercapacitors. J. Power Sources 2019, 424, 108-130. [CrossRef]

101. Acharya, S.; Sahoo, S.; Sonal, S.; Lee, J.H.; Mishra, B.K.; Nayak, G. Adsorbed Cr(VI) based activated carbon/polyaniline nanocomposite: A superior electrode material for asymmetric supercapacitor device. Compos. Part B Eng. 2020, 193, 107913. [CrossRef]

102. Chonat, A.; Palatty, S. Enhanced Electrochemical Performance of a Hybrid Supercapacitive Material Based on Ternary Doped Polyaniline/Activated Carbon Composite. Energy Fuels 2020. [CrossRef]

103. Malkova, A.N.; Sipyagina, N.A.; Gozhikova, I.O.; Dobrovolsky, Y.A.; Konev, D.V.; Baranchikov, A.E.; Ivanova, O.S.; Ukshe, A.E.; Lermontov, S.A. Electrochemical Properties of Carbon Aerogel Electrodes: Dependence on Synthesis Temperature. Molecules 2019, 24, 3847. [CrossRef] [PubMed]

104. Yang, I.; Kwon, D.; Kim, M.-S.; Jung, J.C. A comparative study of activated carbon aerogel and commercial activated carbons as electrode materials for organic electric double-layer capacitors. Carbon 2018, 132, 503-511. [CrossRef]

105. Xu, J.; Zhou, X.; Chen, M.; Shi, S.; Cao, Y. Preparing hierarchical porous carbon aerogels based on enzymatic hydrolysis lignin through ambient drying for supercapacitor electrodes. Microporous. Mesoporous. Mat. 2018, 265, 258-265. [CrossRef]

106. Cai, T.; Kuang, L.; Wang, C.; Jin, C.; Wang, Z.; Sun, Q. Cellulose as an Adhesive for the Synthesis of Carbon Aerogel with a 3D Hierarchical Network Structure for Capacitive Energy Storage. ChemElectroChem 2019, 6, 2586-2594. [CrossRef]

107. Wu, Q.; Hu, J.; Cao, S.; Yu, S.; Huang, L. Heteroatom-doped hierarchical porous carbon aerogels from chitosan for high performance supercapacitors. Int. J. Biol. Macromol. 2020, 155, 131-141. [CrossRef]

108. Jiaming, S.; Wei, L.; Lei, E.; Zhou, X.; Chunhui, M.; Zhenwei, W.; Shouxin, L. Ultralight carbon aerogel with tubular structures and N-containing sandwich-like wall from kapok fibers for supercapacitor electrode materials. J. Power Sources 2019, 438 , 227030-227038.

109. Wang, D.; Wei, F.; Shijia, Y.; Tianxi, L. Improving hierarchical porous structure of carbon aerogels for more efficient ion transport for supercapacitors with commercial level mass loading. Electrochim. Acta 2019, 323, 134811-134820. [CrossRef]

110. Chi, W.; Yanshan, H.; Hao, P.; Jianzhong, J.; Xiangwen, Y.; Zhixiao, X.; Hao, T.; Sheng, H.; Wu, D. Nitrogen-doped porous carbon/graphene aerogel with much enhanced capacitive behaviors. Electrochim. Acta 2016, 215, 100-107.

111. Oschatz, M.; Borchardt, L.; Pinkert, K.; Thieme, S.; Lohe, M.R.; Hoffmann, C.; Benusch, M.; Wisser, F.M.; Ziegler, C.; Giebeler, L.; et al. Hierarchical carbide-derived carbon foams with advanced mesostructure as a versatile electrochemical ener-gy-storage material. Energy Mater. 2014, 4, 1300645. [CrossRef]

112. Rose, M.; Korenblit, Y.; Kockrick, E.; Borchardt, L.; Oschatz, M.; Kaskel, S.; Yushin, G. Hierarchical micro- and meso-porous carbide-derived carbon as a high-performance electrode material in supercapacitors. Small 2011, 7, 1108-1117. [CrossRef]

113. Tallo, I.; Thomberg, T.; Kurig, H.; Jänes, A.; Kontturi, K.; Lust, E. Supercapacitors based on carbide-derived carbons synthesised using $\mathrm{HCl}$ and $\mathrm{Cl} 2$ as reactants. J. Solid State Electrochem. 2012, 17, 19-28. [CrossRef] 